\title{
DEVELOPMENT AND APPLICATION OF A PHYSICALLY BASED LANDSCAPE WATER BALANCE IN THE SWAT MODEL
}

\author{
A Thesis \\ Presented to the Faculty of the Graduate School \\ of Cornell University \\ In Partial Fulfillment of the Requirements for the Degree of \\ Master of Science
}

by

Eric Davidson White

February 2010 
(C) 2010 Eric Davidson White 


\section{ABSTRACT}

The Soil and Water Assessment Tool (SWAT) uses the popular Curve Number (CN) method to determine the respective amounts of infiltration and surface runoff. While appropriate for engineering design in temperate climates, the $\mathrm{CN}$ is less than ideal in monsoonal climates and areas dominated by variable source area hydrology. The $\mathrm{CN}$ methodology is based on the assumption that there is a unique relationship between the average moisture content and the $\mathrm{CN}$ for all hydrologic response units, a questionable assumption in many regions. Rather than using the $\mathrm{CN}$ routine to predict runoff in SWAT, a physically based water balance was added to the code base. To compare this new water balance SWAT (SWAT-WB) to the original CN based SWAT (SWAT-CN), two watersheds were initialized: one in the headwaters of the Blue Nile in Ethiopia and one in the Catskill Mountains of New York State. SWAT-WB's streamflow predictions were significantly better than SWAT-CN in the Ethiopian watershed with validation period NashSutcliffe efficiencies of 0.76 and 0.67 , respectively. SWAT-WB performed better during calibration than SWAT-CN (NSE of 0.64 and 0.43 , respectively) in the Catskills, but was not as accurate during validation (NSE of 0.52 and 0.62 , respectively). While SWAT-WB was generally at least as accurate, if not more so, than SWAT-CN at the watershed outlets, it provided much more realistic spatial distribution of runoff producing areas. These results suggest that replacement of the $\mathrm{CN}$ with a water balance routine in SWAT: significantly improves model predictions in monsoonal climates, provides equally acceptable levels of accuracy under more typical US conditions, while at the same time greatly improving the ability to predict spatial distribution of runoff contributing areas. 


\section{BIOGRAPHICAL SKETCH}

Eric White was born in 1984 in East Berlin, a small town in the countryside of south-central Pennsylvania. Upon graduation from high school, he attended The Pennsylvania State University at University Park, where he obtained his BS in Agricultural \& Biological Engineering in 2007. Planning to attend graduate school in the fall, Eric took a temporary position with the Pasture Systems and Watershed Management Research Unit, which is a division of the USDA's Agricultural Research Service. His research there dealt with watershed modeling and provided a smooth transition into his graduate studies with Cornell University's Soil and Water Lab. 
Many thanks to my parents for their unwavering love, encouragement, and support; my sisters for being the wonderful women that they have grown to be; and finally my partner Amelia, whose love and friendship is a much appreciated constant in my life. 


\section{ACKNOWLEDGEMENTS}

First and foremost, I am grateful to my advisor, Dr. Tammo Steenhuis, for providing me not only with a wonderful opportunity, but also providing me with a thoroughly enjoyable and rewarding project to work on. I would also like to thank the many members of Cornell's Soil and Water Lab who have provided insight, support, and friendship throughout my time with them. Additionally, I am indebted to both Dr. Zach Easton and Daniel Fuka for the invaluable assistance that they have provided over the past two years.

This thesis was developed under a STAR Research Assistance Agreement No. FP916984 awarded by the U.S. Environmental Protection Agency. It has not been formally reviewed by the EPA. The views expressed in this document are solely those of the authors and the EPA does not endorse any products or commercial services mentioned in this document. Additional support was received from the Mario Einaudi Center for International Studies, as well as the International Water Management Institute (IWMI) managed project PN19, 'Upstream-Downstream in the Blue Nile' funded through the CGIAR Challenge Program on Water and Food. 


\section{TABLE OF CONTENTS}

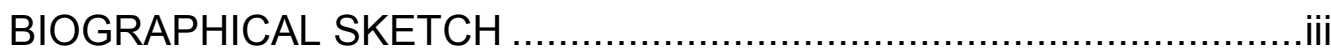

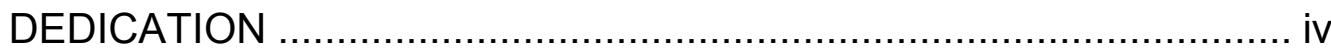

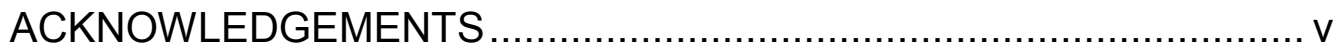

TABLE OF CONTENTS $\ldots \ldots \ldots \ldots \ldots \ldots \ldots \ldots \ldots \ldots \ldots \ldots \ldots \ldots \ldots \ldots \ldots \ldots . \ldots \ldots$

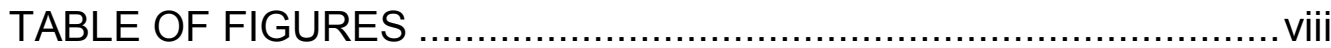

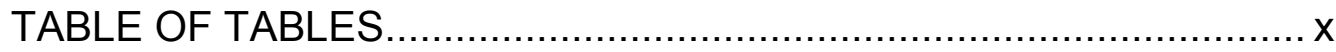

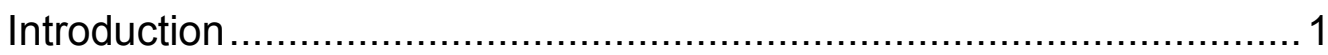

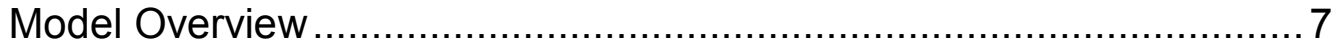

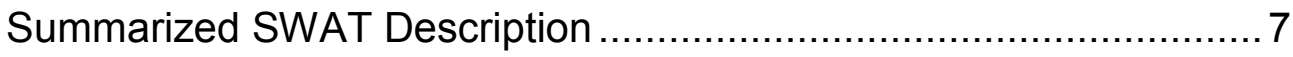

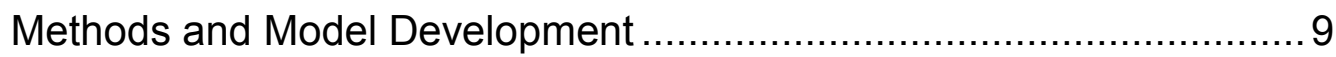

Curve Number Approach................................................ 9

Water Balance Approach................................................ 9

HRU Definition............................................................... 11

Watershed Descriptions ...................................................... 15

Gumera Basin, Blue Nile Watershed, Ethiopia....................... 15

Townbrook Watershed, Catskills, New York ............................ 17

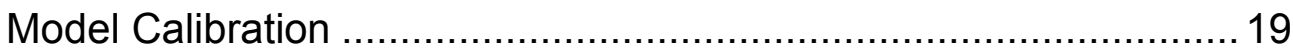

Model Validation ......................................................... 20

Model Evaluation ................................................................. 20

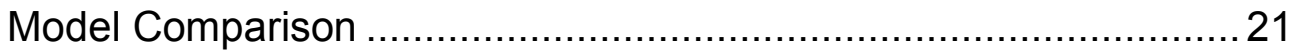




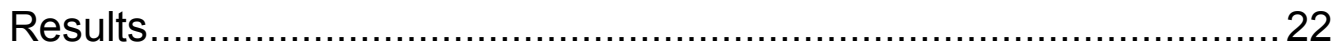

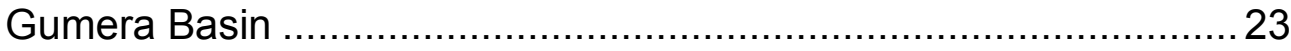

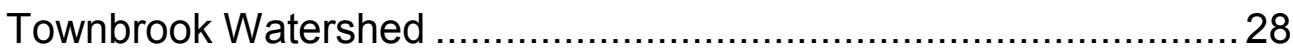

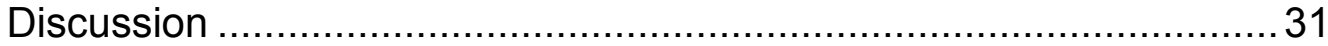

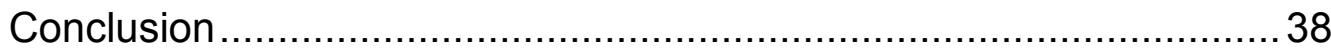

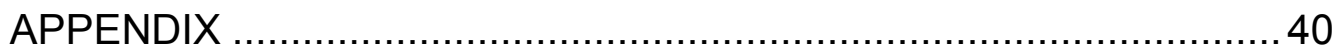

SWAT-WB User Manual..................................................... 41

SWAT-WB Theoretical Documentation ................................ 49

Water Balance Approach Used by SWAT-WB ......................... 51

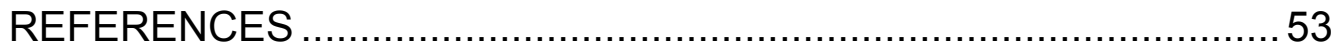




\section{LIST OF FIGURES}

Figure 1. CN predicted runoff for Anjeni, Ethiopia, grouped in ranges of

cumlative rainfall. 4

Figure 2. Default HRU definition process in SWAT.

Figure 3. HRU definition process developed for SWAT-VSA and used in SWAT-WB. 14

Figure 4. Wetness classes for Gumera, Ethiopia. 14

Figure 5. Elevation of the Gumera Basin, located east of Lake Tana in the Ethiopian Highlands. 16

Figure 6. Temperature data used for modeling the Gumera watershed. 17

Figure 7. Precipitation and observed streamflow data used for modeling

Gumera. 17

Figure 8. Wetness classes for Townbrook, located in the Catskill

Mountains of New York State.

Figure 9. Observed and modeled streamflow for a) Gumera and b)

Townbrook.

Figure 10. Observed and modeled hydrograph for Gumera during validation period. 25

Figure 11. SWAT-WB modeled streamflow versus observed streamflow for Gumera, during valdiation period. 25

Figure 12. Spatial distribution of surface runoff in Gumera modeled by: A) SWAT-CN and B) SWAT-WB. 27

Figure 13. Observed and modeled hydrograph for Townbrook during the validation period. 28

Figure 14. Spatial distribution of surface runoff in Townbrook modeled by:

A) SWAT-WB, B) SWAT-VSA, and C) SWAT-CN. 30 
Figure 15. Major soil types in the Gumera basin. .................................. 35

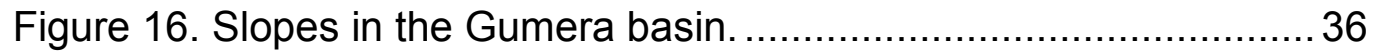

Figure 1. After all input files are written in the GIS interface, select the

Run SWAT button.

Figure 2. Set final parameters and click Setup SWAT Run.

Figure 3. After clicking Setup SWAT Run, the project is ready to be modified for use with SWAT-WB.

Figure 4. Location of the TxtInOut folder containing all text input files. In the above figure, C:IResearchlgumeraswat will be replaced by the location of the specific project directory created during the project setup.

Figure 5. The TxtInOut folder containing the input files developed during the project setup stage. 45

Figure 6. The TxtInOut folder containing the files needed to run SWATWB. 45

Figure 7. Accessing Windows Command Prompt either from Start Menu>All Programs>Accessories $(A)$ or from the Run tool (B).

Figure 8. Navigating to project directory with Command Prompt and running SWAT-WB. 


\section{LIST OF TABLES}

Table 1. Overall model statistics for daily streamflow in Gumera Basin. 24

Table 2. Yearly model statistics for daily streamflow in Gumera Basin, as

modeled with SWAT-WB ............................................. 24

Table 3. Overall model statistics for daily streamflow in Townbrook. ..... 28 


\section{Introduction}

Many regulations are in place to monitor point-sources of pollution (i.e. industrial sites, waste water treatment plants, etc.), but it is well understood that these point-sources are not the only factor in diminishing water quality values. Urban and agricultural runoff can contribute significant quantities of nutrients, chemicals, and sediments into stream networks, negatively impacting water bodies. To locate these "non-point" sources of pollution in a landscape, many watershed managers and researchers frequently use watershed scale models. One of the most commonly used watershed scale models being used is the USDA's Soil \& Water Assessment Tool (SWAT) model.

SWAT, like any water quality model, must first accurately simulate hydrologic processes before it can be used to model pollutant transport. Many different approaches to modeling hydrologic processes have been presented in the scientific literature over the past several decades, but SWAT currently uses two methods to model surface runoff: the curve number $(\mathrm{CN})$ and the Green-Ampt routine. While the Green-Ampt method is a well accepted, physically-based infiltration excess, rainfall-runoff model, it can be difficult to use in data scarce regions. The empirical $\mathrm{CN}$ method enjoys much wider use in the SWAT model, due to its ease of use and simplifying assumptions (King et al., 1999; Gassman, 2005).

While the $\mathrm{CN}$ method is easy to use, returns acceptable results in many cases for discharge at the watershed outlet, and is supported by agencies in the United States, researchers have long voiced concerns over its use in watershed models (Bosznay, 1989; Hjelmfelt, 1991; Woodward and Cronshey, 
1991; Steenhuis et al., 1995, among others). Ponce and Hawkins (1996) have gone as far as to say of the method: "Barring appropriate modifications, the [CN] method should not be used to model the long-term hydrologic response of a catchment. Nevertheless, it is recognized that the method has been used in several long-term hydrologic simulation models developed in the past two decades with varying degrees of success."

Useful for engineering design of flood control structures, this empirical approach does not differentiate between runoff generating processes (saturation excess vs. infiltration excess) and therefore has been shown to be less than ideal when used to simulate spatial variation in runoff generation. While the $\mathrm{CN}$ method can be rewritten as a saturation excess model (Steenhuis et al., 1995), it relies on a statistical relationship between soil moisture condition and $\mathrm{CN}$ value that was never tested in areas where long periods of rain can lead to prolonged soil saturation (see Garen and Moore, 2005 for a full, more recent, critique).

In addition to these general problems, the $\mathrm{CN}$ was developed as a statistical summary of standard plot data and infiltrometer tests from only a few southern/southwestern locations within the United States (Ponce and Hawkins, 1996). Therefore, the $\mathrm{CN}$ method is not valid for other regions unless specifically validated for these regions. Nevertheless, SWAT and other CNbased models are frequently being used on watersheds around the world where the climate and landscape vary greatly from that of the United States. SWAT alone has been used to model watersheds in places as diverse as China, India, Australia, the UK, France, Belgium, Algeria, Tunisia, Italy, and Greece with little acknowledgement that the underlying runoff calculations were never validated for these regions (Gassman et al., 2007). 
Another region where the $\mathrm{CN}$ method has been applied is in the Blue Nile watershed. Located in the monsoonal climate of the Ethiopian highlands, the Blue Nile watershed's temporal runoff dynamics are poorly captured by the $\mathrm{CN}$ technique. Previous work in this watershed has shown that for a given amount of rain, runoff volumes will vary throughout the rainy season. Less runoff is generated at the beginning of the rainy season as compared to the same rain event at the end of the season, an observation that invalidates the underlying assumption of the $\mathrm{CN}$ method that rainfall is the sole factor in runoff generation (Liu et al., 2008).

This point is illustrated in Figure 1, where the standard CN approach was applied to the 113 hectare Anjeni watershed, a heavily cultivated catchment in the Ethiopian highlands. When the method was calibrated to rainfall-runoff events at the end of the rainy season, the model poorly predicted events at the beginning of the season. Runoff events that occurred prior to $500 \mathrm{~mm}$ of cumulative effective precipitation (precipitation minus evapotranspiration) were consistently under-predicted, whereas the model performed better once sufficient rainfall had fallen. This is in direct contrast to the official method's literature, which states that there is no correlation beyond five days of antecedent precipitation and a watershed's maximum retention (NRCS, 2004). 


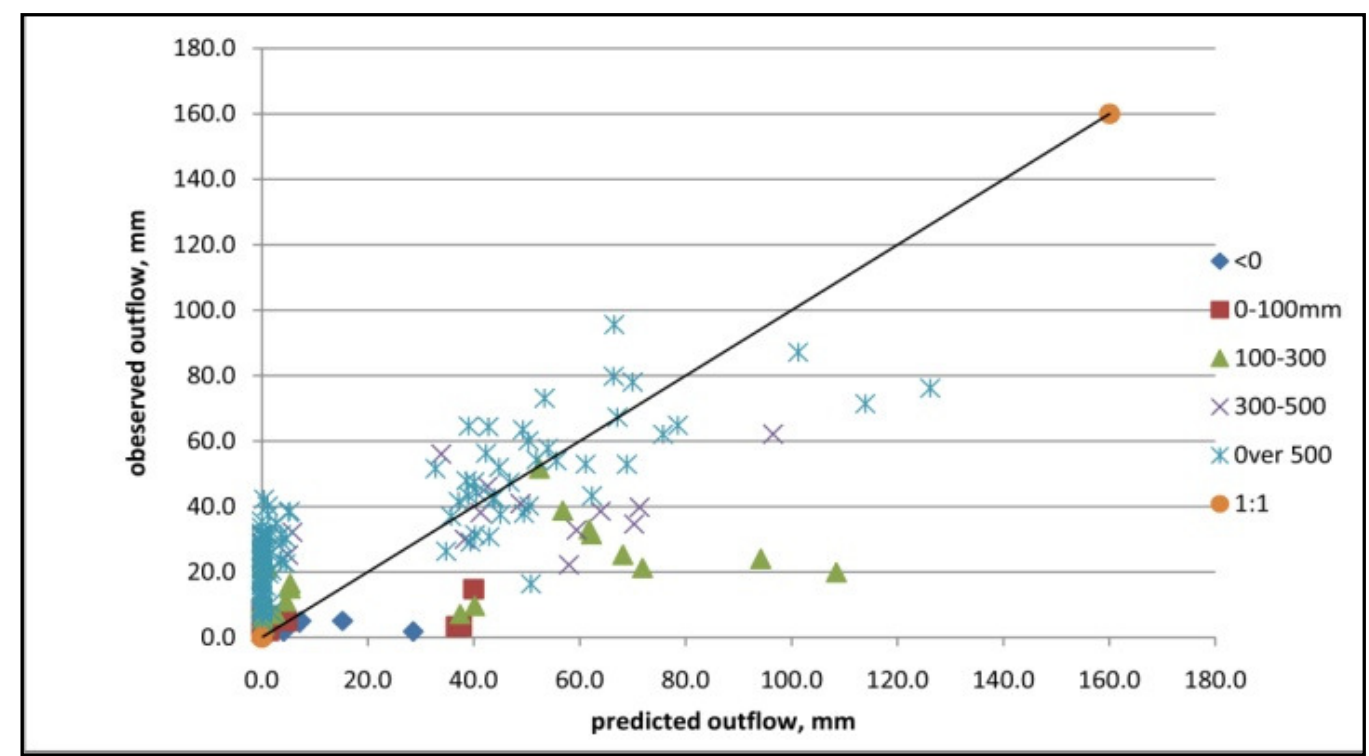

Figure 1. CN predicted runoff for Anjeni, Ethiopia, grouped in ranges of cumlative rainfall.

The fact that parameters used in the $\mathrm{CN}$ method change through time has been examined for other watersheds in various climates around the world. Many researchers have proposed adjustments, and in some cases, the $\mathrm{CN}$ method was actually modified to better capture runoff dynamics. For instance, Bryant et al. (2006) suggest that a watershed's initial abstraction, the volume of rain after which runoff will occur, should vary as a function of storm size. While this is a valid argument, the introduction of another variable reduces the appeal of the one-parameter $\mathrm{CN}$ model, adding further doubt as to whether the $\mathrm{CN}$ approach is the best technique for temporal hydrologic modeling.

Time-dependent adjustments to the $\mathrm{CN}$ method applied to SWAT range from sub-daily alterations to seasonal changes. SWAT was more accurate when $\mathrm{CN}$ values are averaged across each day of simulation, rather than using a $\mathrm{CN}$ that described moisture conditions only at the start of each day (Kim and Lee, 2008). SWAT results also improved when the CN was changed 
seasonally to account for watershed storage variation due to plant growth and dormancy (White et al., 2009). While these temporal CN adjustments result in more accurate simulations, neither one of these approaches can account for the extreme antecedent moisture conditions that are found in monsoonal climates. Wang et al. (2008) improved SWAT results by using a different relationship between antecedent conditions and watershed storage, but since no change was made to the range of antecedent conditions taken into account, these adjustments ultimately do not address the shortcomings of the $\mathrm{CN}$ in monsoonal climates.

While few, if any, existing temporal adjustments are useful for $\mathrm{CN}$ application in an Ethiopian watershed, spatial modifications that have been reported in the literature can be applied, which will potentially improve SWAT results. It is well understood that, under many situations, surface runoff is contributed by only a portion of a watershed. This concept is often referred to as a variable source area (VSA); a phenomenon actually envisioned by the original developers of the method (Hawkins, 1979), but never implemented in the original $\mathrm{CN}$ method as used by the NRCS in its handbooks. Since the method's inception, numerous attempts have been made to justify its use in modeling VSA-dominated watersheds. These adjustments range from simply assigning different $\mathrm{CNs}$ for wet and dry portions to correspond with VSAs (Sheridan and Shirmohammadi, 1986; White et al., 2009), to full reinterpretations of the original CN method (Hawkins, 1979; Steenhuis et al., 1995; Easton et al., 2008).

Contrary to the more simple approach of merely changing $\mathrm{CNs}$ to account for contributing areas, the $\mathrm{CN}$ method can actually be manipulated to determine exactly what portion of a watershed is responsible for surface runoff 
generation (Steenhuis et al., 1995). It has been shown that this known contributing portion of a watershed can then be accurately modeled spatially by linking this $\mathrm{CN}$ method with a topographic index $(\mathrm{TI})$, similar to those used by the topographically driven TOPMODEL (Beven and Kirkby, 1979; Lyon et al., 2004). This linked CN-TI method has since been used in multiple models of watersheds in the northeastern US, including the Generalized Watershed Loading Function (GWLF) (Schneiderman et al., 2007) and SWAT (Easton et al., 2008).

SWAT-VSA, the CN-TI adjusted version of SWAT, returned hydrologic simulations as accurate as the original $\mathrm{CN}$ method, however the spatial predictions of runoff producing areas were much more accurate. By improving spatial representation of runoff within the watershed, SWAT-VSA also returns improved simulations of water quality within the watershed. SWAT-VSA vastly improves SWAT's ability to predict where specific nutrients and/or pollutants are being generated, resulting in a powerful tool to mitigate non-point source pollution (Easton et al., 2008).

While SWAT-VSA is a vast improvement upon the original method in watersheds where topography drives flows, ultimately, it still relies upon the $\mathrm{CN}$ to model runoff processes and therefore falls short when applied to the monsoonal Ethiopian highlands. In past efforts, advanced models, such as SWAT, are rarely applied to the Blue Nile; instead, less complex models are frequently used to model this watershed. Water balance models are relatively simple to implement and have been used frequently in the Blue Nile watershed (Johnson and Curtis, 1994; Conway, 1997; Ayenew and Gebreegziabher, 2006; Liu et al., 2008; and Kim and Kaluarachchi, 2008). While these water balance models vary in complexity, they enable researchers to understand the 
underlying hydrologic processes of the watershed. Furthermore, unlike the $\mathrm{CN}$ method, these water balance models are useful in any climate where rainfall intensity is generally less than the soils infiltration capacity.

By incorporating elements from these successful water balance models with the spatial adjustments proposed by Lyon et al. (2004) and implemented by Easton et al. (2008) into SWAT-VSA, we propose and test a CN-free version of SWAT. This new version of SWAT, SWAT-WB, calculates runoff volumes based on exceeding saturation in a water balance and can lead to more accurate simulation of where runoff occurs in watersheds dominated by saturation-excess processes. Both the original CN method used by SWAT and the new, water balance (SWAT-WB) method are tested on two watersheds which vary widely in climate, geology, and data availability: one in the Blue Nile Watershed in Ethiopia, and one in the Catskill Mountains of New York State.

\section{Model Overview}

To improve SWAT performance in areas dominated by saturationexcess runoff processes, a new runoff routine was added to SWAT. A daily soil water balance was used to determine the saturation deficit of each hydrologic response unit (HRU) in SWAT, which was then used, instead of the $\mathrm{CN}$ method, to determine daily runoff volume.

\section{Summarized SWAT Description}

SWAT is a basin-scale model designed to simulate hydrologic processes, nutrient cycling, and sediment transport throughout a watershed. Catchment area varies widely throughout the peer-reviewed literature, with 
SWAT being used on watersheds as small as $0.15 \mathrm{~km}^{2}$ (Chanasyk et al., 2003) and as large as $491,700 \mathrm{~km}^{2}$ (Arnold et al., 2000). From a digital elevation model (DEM), the watershed will be divided into subbasins that are assigned a stream channel, or reach in SWAT terminology. If the locations of stream gauges are known, the user can choose to have the subbasin outlets correspond to these gauges. Similarly, if a stream network has been previously mapped, this network can be used. If no such data is available, SWAT will determine the stream network from the DEM. All of these processes can be performed via a geographical information system (GIS) interface for SWAT. The ArcSWAT 2.0 interface for ArcGIS 9.2 was used for this project.

For each day of simulation, SWAT models processes such as: rainfall, runoff, infiltration, plant dynamics (including uptake of water and nutrients, biomass, etc.), erosion, nutrient cycling, leaching of pesticides and nutrients, and many others. In addition to the physical processes, users can model scheduled crop rotations, irrigation, fertilizer application, tillage, and harvesting. To increase computing efficiency, SWAT does not distribute these processes throughout the entire watershed. Instead, SWAT models these processes only once for each unique portion of the watershed. To determine these unique areas, SWAT utilizes hydrologic response units (HRUs). Each subbasin of a watershed is divided into HRUs, which are traditionally defined as the coincidence of soil type and landuse. The HRU is the smallest unit in the SWAT model and is used to simulate all of the processes mentioned above. These HRU simulation results are combined for each subbasin, and then routed through the watershed's stream network. 


\section{Methods and Model Development}

\section{Curve Number Approach}

An initial $\mathrm{CN}$ is assigned for each specific landuse/soil combination in the watershed, and these values are read into the SWAT program. SWAT then calculates upper and lower limits for each $\mathrm{CN}$ following a probability function described by the NRCS to account for varying antecedent moisture conditions (CN-AMC) (USDA-NRCS, 2004). SWAT determines an appropriate $\mathrm{CN}$ for each simulated day by using this CN-AMC distribution in conjunction with daily soil moisture values determined by the model. This daily $\mathrm{CN}$ is then used to determine a theoretical storage capacity, $S$, of the watershed for each day the

model is run. The storage is then indirectly used to calculate runoff volume, $Q$ :

$$
\begin{aligned}
& C N=\frac{1000}{10+S / 25.4} \\
& Q=\frac{\left(P-I_{a}\right)^{2}}{\left(P-I_{a}\right)+S}
\end{aligned}
$$

eq. 1

eq. 2

where $S$ is watershed storage, $P$ is precipitation, and $l_{a}$ is initial abstraction. All terms are in $\mathrm{mm}$ of water, and by convention $l_{a}$ is assumed to be equal to $0.2 * S$.

\section{Water Balance Approach}

To replace the $\mathrm{CN}$, a simple soil profile water balance was calculated for each day of simulation. While SWAT's soil moisture routine greatly simplifies processes that govern water movement through porous media (in 
particular, partly-saturated regions), for a daily model the approach can be shown to be acceptable (Guswa et al., 2002). These inherent soil moisture routines are then used by SWAT-WB to determine the degree of saturationdeficit for each soil profile for each day of simulation. This saturation-deficit (in $\mathrm{mm} \mathrm{H}_{2} \mathrm{O}$ ) is termed the available soil storage, $r$ :

$$
\tau=E D C(\varepsilon-\theta)
$$

where $E D C$ is the effective depth of the soil profile (unitless), $\varepsilon$ is the total soil porosity ( $\mathrm{mm}$ ), and $\theta$ is the volumetric soil moisture for each day ( $\mathrm{mm})$. The porosity is a constant value for each soil type, whereas $\theta$ varies by the day and is determined by SWAT's soil moisture routines. The effective depth, $E D C$, a calibration parameter ranging from zero to one, is used to represent the portion of the soil profile used in calculating the saturation deficit. By including this adjustment to the available storage, the amount of water able to infiltrate each day will be controlled by the EDC. EDC will then be spatially varied in such a way that low values are assigned to areas with a high likelihood of saturation, and higher EDCs will be used for areas where not much surface runoff is generated via saturation excess. This spatially adjusted available storage is then used to determine what portion of rainfall events will infiltrate and what portion will runoff:

$$
Q=\left\{\begin{array}{cc}
0, & \text { if } P<\tau \\
P-\tau, & \text { if } P \geq \tau
\end{array}\right.
$$

eq. 4

where $Q$ is surface runoff $(\mathrm{mm})$ and $P$ is precipitation $(\mathrm{mm})$. 
The available storage, $T$, is calculated each day prior to the start of any rain event. Once precipitation starts, a portion of the rain, equal in volume to $T$, will infiltrate the soil. If the rain event is larger in volume than $T$, the soil profile will be saturated and surface runoff will occur. If the rain event is less than $T$, the soil will not be saturated and there will be no surface runoff. By using this simple saturation-deficit term, SWAT-WB represents saturation-excess process and is no longer reliant upon the $\mathrm{CN}$ method.

\section{HRU Definition}

HRUs are defined in SWAT as being unique occurrences of soil type, land cover, and slope class (see Figure 2). Any parcels of land within one subbasin that share the same combination of these three features will be considered one HRU. All processes modeled by SWAT are done so for each unique HRU in the watershed, independent of position within each subbasin. In basins dominated by VSA hydrology this HRU definition has been shown to be a less than ideal means of describing the spatial and temporal evolution of hydrologic processes (Schneiderman et al., 2007; Easton et al., 2008). In VSA watersheds runoff-generating areas are likely to occur in portions of the landscape with shallow, low conductive soils,, large contributing areas, and gentle slopes. While SWAT's inclusion of slope classes in HRU delineation

begins to address these issues, there is currently no way to include upslope contributing area while defining HRUs. To correct for this, a soil topographic index (STI) was integrated with existing soils data in the HRU definition process (Easton et al., 2008). 


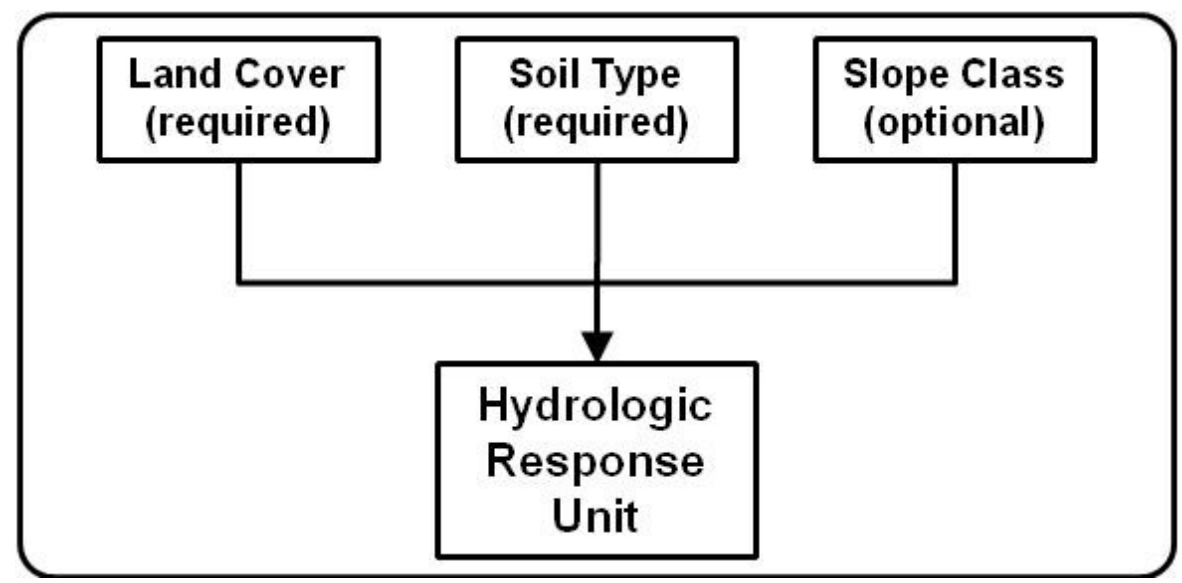

Figure 2. Default HRU definition process in SWAT.

Soil topographic indices have been used to model runoff-contributing areas for quite some time and an important facet of the physically-based TOPMODEL (Beven and Kirkby, 1979). Recently, soil topographic indices have been incorporated into $\mathrm{CN}$-based watershed models for use in VSA dominated regions (Lyon et al., 2004; Schneiderman et al., 2007; Easton et al., 2008). SWAT-VSA integrated STIs into SWAT in order to improve determination of runoff-generating areas and the subsequent nutrient loads from these areas in the Catskills Mountains of New York State (Easton et al., 2008). SWAT-VSA provided more accurate predictions of runoff source areas (as validated by water table measurements) than the original SWAT, and its HRU definition process was included in SWAT-WB.

To initialize SWAT-WB the first step was to create a soil topographic index for the watershed being modeled. The STI is defined as:

$$
S T I=\ln \left(\frac{A}{\tan (\beta) D K_{s}}\right)
$$

eq. 5 
The upslope contributing area, $A$, and the slope, $\tan (\beta)$, are both obtained from a DEM, while the soil depth, $D$, and saturated hydraulic conductivity, $K_{s}$, are obtained from a soil survey. We assume that STI values relate to a location's likelihood of saturation, and therefore the likelihood to contribute surface runoff. Higher STI values are the result of either a large contributing area, or small values for slope, soil depth, or saturated conductivity, and therefore are indicative of areas with a higher probability for saturation.

Following the process outlined for SWAT-VSA, the STI is then reclassified into wetness classes of equal area, which represent a location's likelihood to saturate. This wetness class is then substituted for a soils map in the HRU definition process (see Figure 3). While the wetness classes can be used in HRU delineation instead of a soil map, SWAT still requires specific soil properties that are commonly associated with the soils map (e.g., SSURGO Database). Thus in SWAT-WB soil properties required by SWAT were areally weighted and averaged for each wetness class. This practice will not drastically affect model results for two reasons. First, in Ethiopia, soil survey information is extremely difficult to find, if it exists at all, and, to our knowledge no defined database that would contain the parameters needed by SWAT exists. To create the SWAT model, the UN-FAO's World's Soil Map was used, which classifies only five distinct soil types in all of the $1270 \mathrm{~km}^{2}$ Blue Nile subcatchment modeled. Second, in New York State, where soils information is more readily available, soil formation (in glaciated areas) is at least partially driven by topography (Page et al., 2005; Sharma et al., 2006; Thompson et al., 2006). Therefore, by averaging across topographic features, as the STI does, inaccuracies in soil properties will be minimized. 


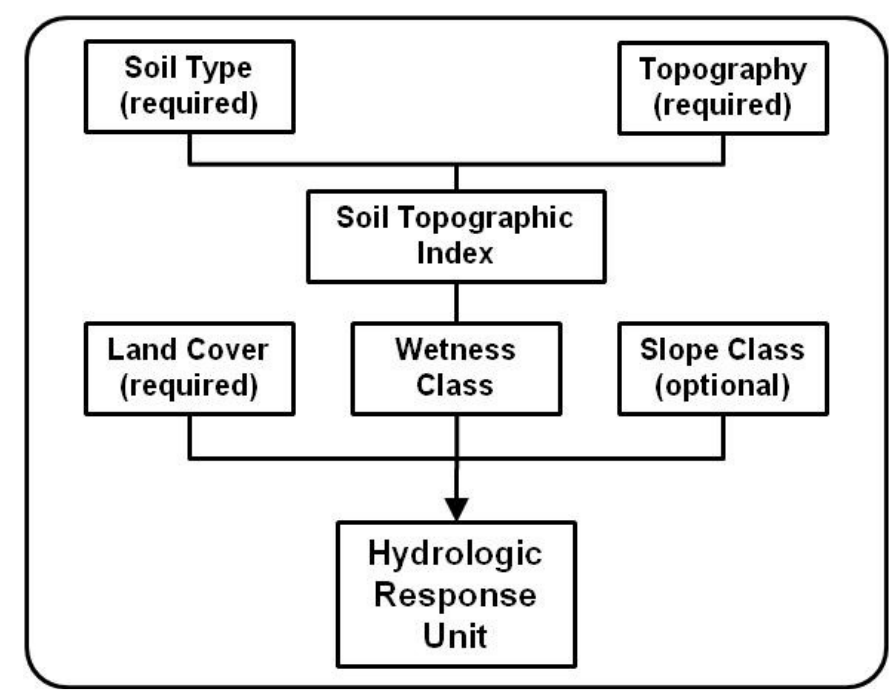

Figure 3. HRU definition process developed for SWAT-VSA and used in SWAT-WB.

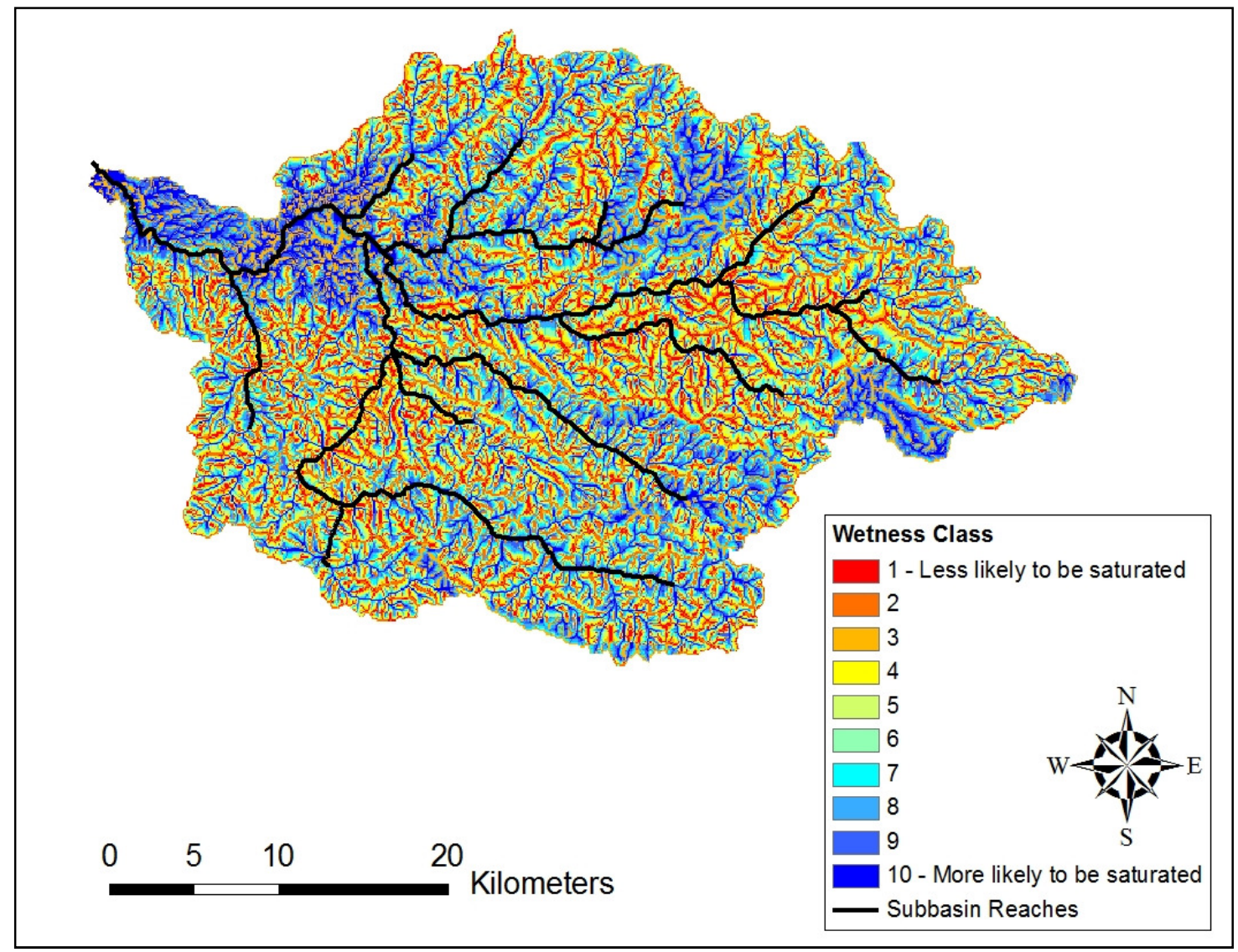

Figure 4. Wetness classes for Gumera, Ethiopia. 


\section{Watershed Descriptions}

Gumera Basin, Blue Nile Watershed, Ethiopia

The new SWAT-WB was initially tested on the Gumera River watershed, a heavily cultivated region in the Ethiopian highlands. Located approximately $30 \mathrm{~km}$ northeast of Bahir Dar; this $1270 \mathrm{~km}^{2}$ watershed drains into Lake Tana, the primary water source for the Blue Nile (Figure 5). Land use coverage indicated that $96 \%$ of the Gumera watershed was agriculture, while $4 \%$ was brush (or pasture). Elevation of the Gumera watershed was determined from a 90 meter grid DEM (source). The watershed ranged from 1797 to 3708 meters above sea level with slopes ranging from $0 \%$ to $79 \%$, with a median, mean and standard deviation of $11 \%, 13 \%$, and $9 \%$, respectively. Predominant soils were gathered from the World Soils map and were classified as haplic and chromic luvisols (58\% and $22 \%$, respectively). Other soils present in the basin were eutric fluvisols (8\%), eutric leptosols $(8 \%)$, eutric vertisols $(3 \%)$, with minimal areas classified as urban $(>1 \%)$ (FAO-AGL, 2003). 


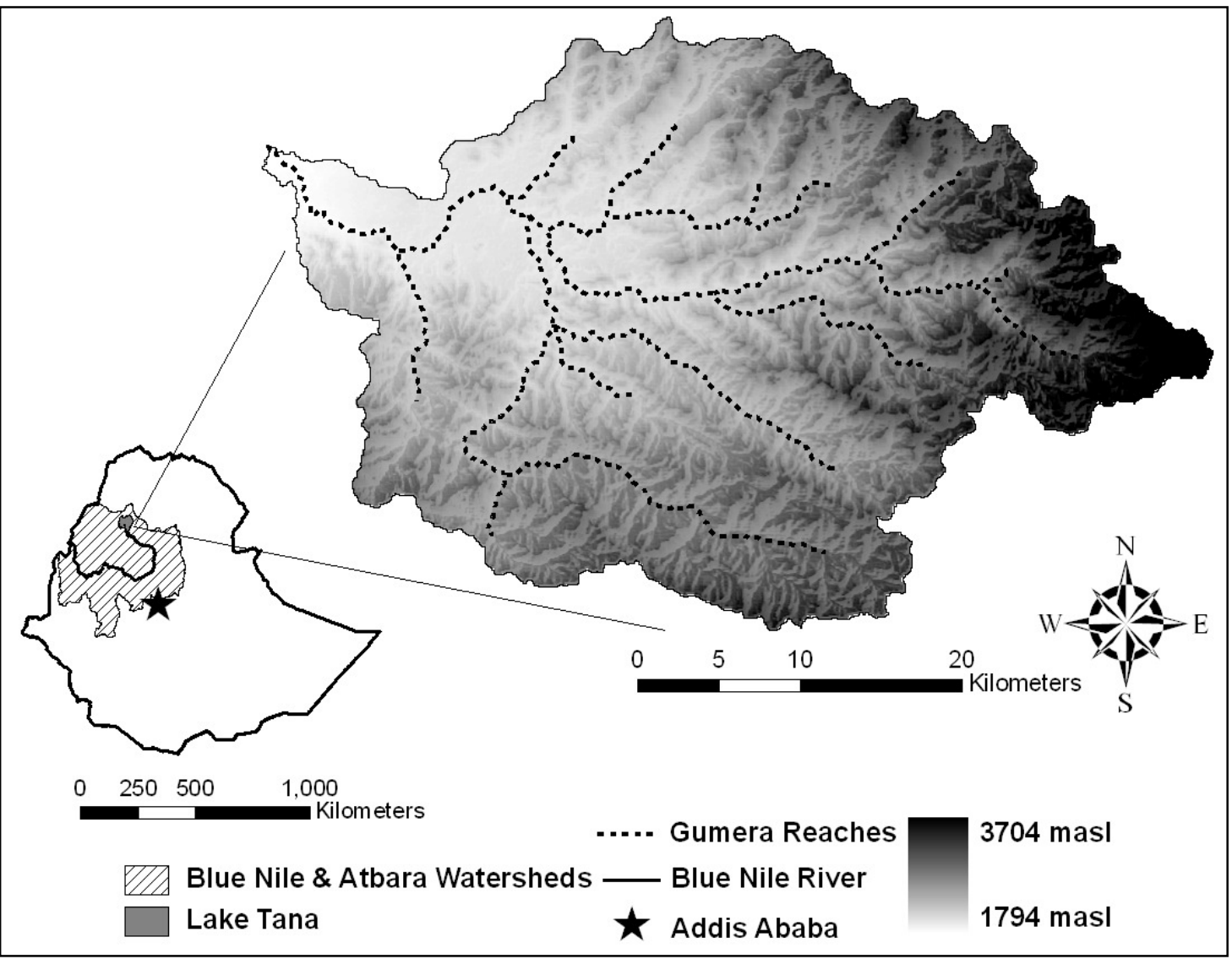

Figure 5. Elevation of the Gumera Basin, located east of Lake Tana in the Ethiopian Highlands.

Precipitation and temperature information was gathered from the National Meteorological Agency of Ethiopia for the Debre Tabor station, the closest rain gauge to the Gumera basin. Precipitation data from 1992 through 2003 was used for model calibration and validation. Other required climatic data included relative humidity, wind speed, and solar radiation. These data were obtained for the nearby city of Bahir Dar through the United States' National Climatic Data Center (NCDC, 2007). 


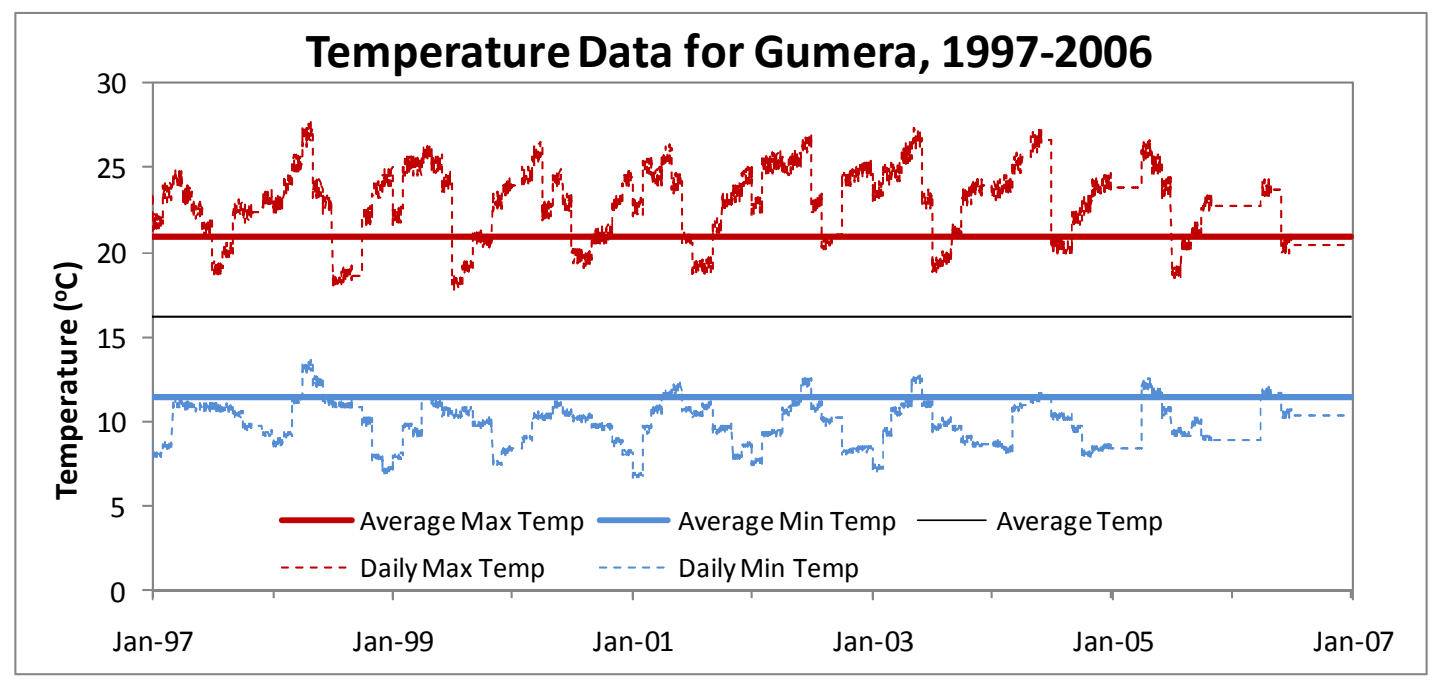

Figure 6. Temperature data used for modeling the Gumera watershed.

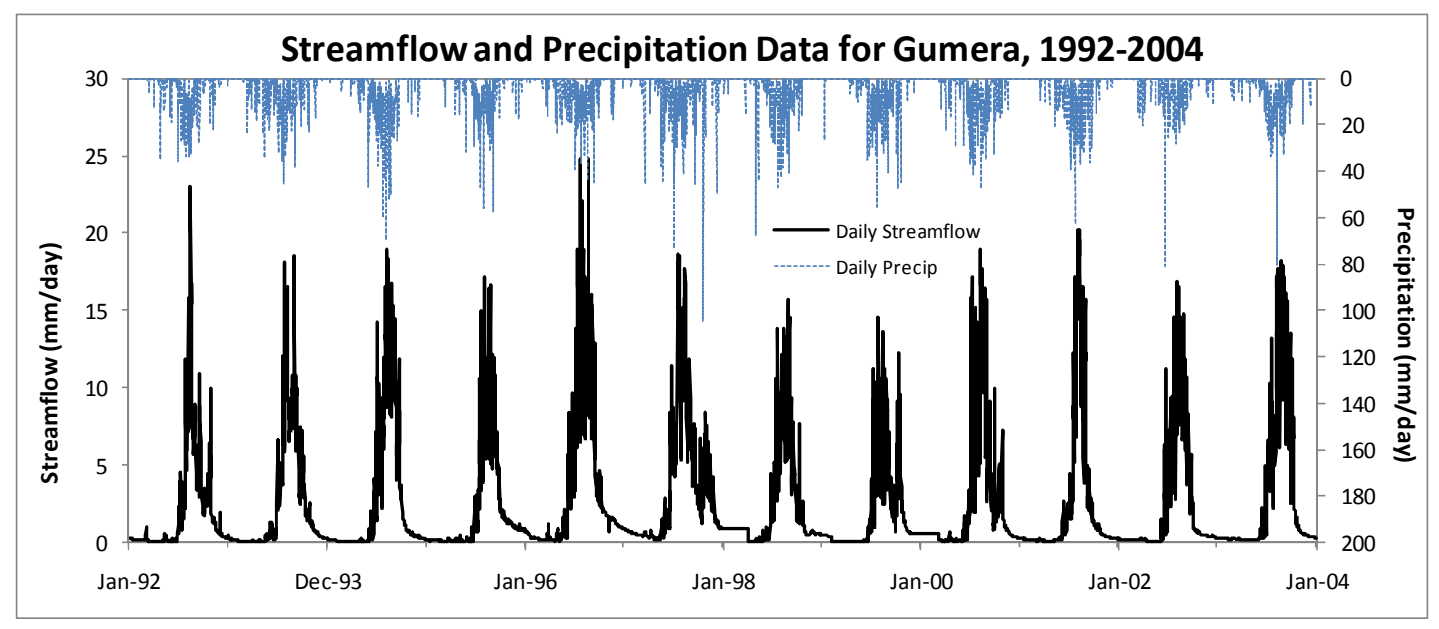

Figure 7. Precipitation and observed streamflow data used for modeling

\section{Gumera.}

Townbrook Watershed, Catskills, New York

SWAT-WB was also tested on the Townbrook watershed in the United States, a $37 \mathrm{~km}^{2}$ sub-catchment of the Cannonsville Reservoir Basin. The region is typified by steep to moderate hillslopes of glacial origins with shallow 
permeable soils, underlain by a restrictive layer. The climate is humid with an average annual temperature of $8^{\circ} \mathrm{C}$ and average annual precipitation of 1123 $\mathrm{mm}$. Elevation in the watershed ranges from 493 to $989 \mathrm{~m}$ above mean sea level. The slopes are quite steep with a maximum of $91 \%$, a mean of $21 \%$ (with a standard deviation of $13 \%$ ), and a median of $18 \%$. Soils are mainly silt loam or silty clay loam with soil hydrologic group $C$ ratings (USDA-NRCS, 2000). Soil depth ranges from less than $50 \mathrm{~cm}$ to greater than $1 \mathrm{~m}$ and is underlain by fragipan restricting layer (e.g. coarse-loamy, mixed, active, mesic, to frigid Typic Fragiudepts, Lytic or Typic Dystrudepts common to glacial tills) (Schneiderman et al., 2002). The lowland portion of the watershed is predominantly agricultural, consisting of pasture and row crops $(20 \%)$ or shrub land $(18 \%)$ while the upper slopes are forested $(60 \%)$. Water and wetland comprise (2\%). Impervious surfaces occupy $<1 \%$ of the watershed and were thus excluded from consideration in the model. Several studies in this watershed or nearby watersheds have shown that variable source areas control overland flow generation (Frankenberger et al., 1999; Mehta et al., 2004; Lyon et al., 2006a, 2006b; Schneiderman et al., 2007; Easton et al., 2008) and that infiltration-excess runoff is rare (Walter et al., 2003). 


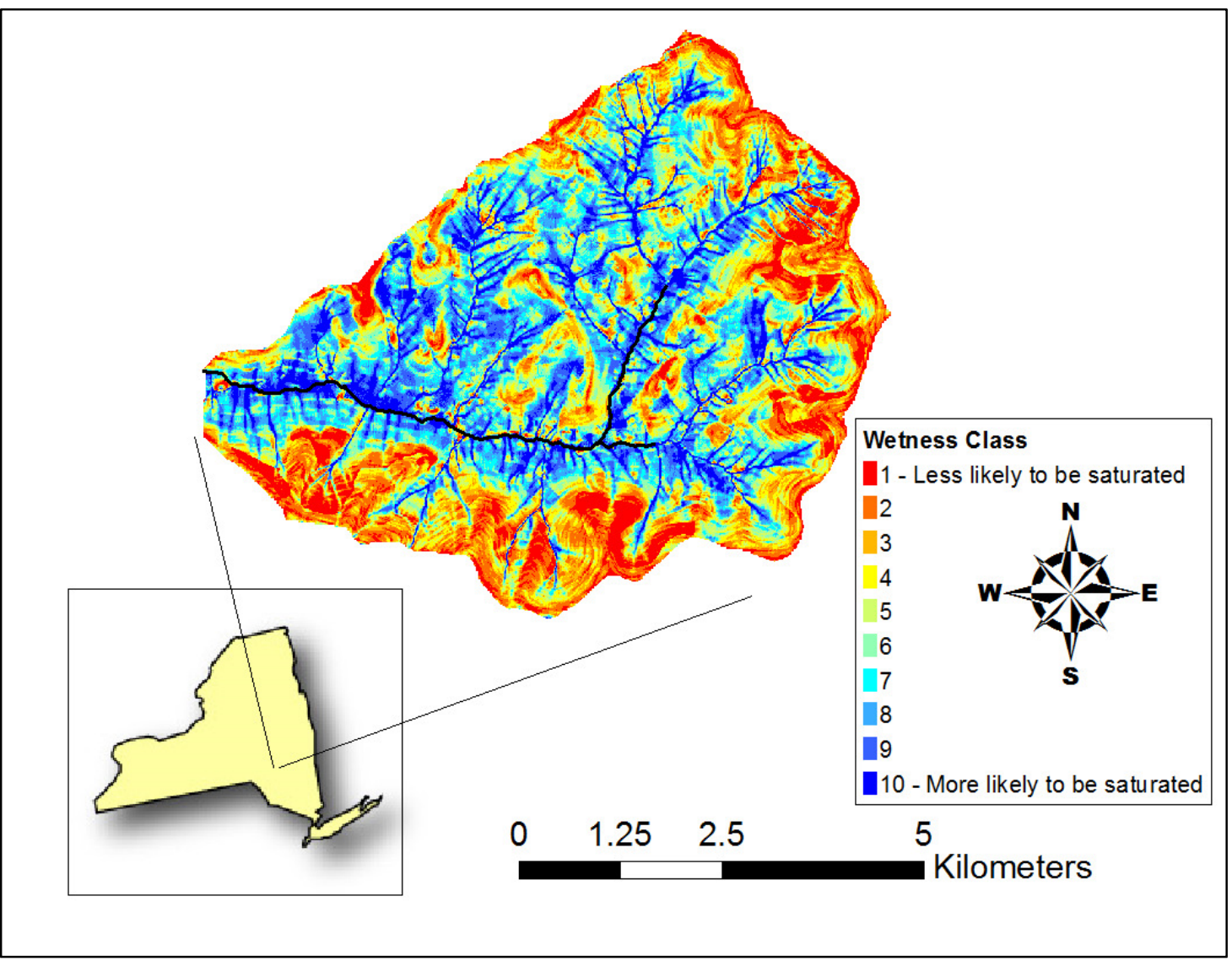

Figure 8. Wetness classes for Townbrook, located in the Catskill Mountains of New York State.

\section{Model Calibration}

Calibration is a crucial step in creating a hydrologic model that returns results both accurate and realistic in simulating the physical processes occurring in the watershed. Tolson and Shoemaker (2005) presented an efficient calibration routine for SWAT, the Dynamically Dimensioned Search (DDS) algorithm, which was used to calibrate SWAT-WB. This DDS autocalibration routine allows for parameters to be calibrated at the watershed, subbasin, HRU, or wetness class level, which in turn allowed for EDC to be calibrated separately for each wetness class. In addition to calibrating an EDC 
for each wetness class, 11 other hydrologic parameters were calibrated in SWAT-WB: SURLAG, GW_DELAY, ALPHA_BF, GWQMN, GW_REVAP, REVAPMN, AWC, KSAT, LAT_TTIME, ESCO, EPCO.

Using DDS (Tolson and Shoemaker, 2004), the streamflow at the Gumera watershed outlet was calibrated over a period of eight years, 1996 to 2003. Townbrook was calibrated from 1998 to 2002.

\section{Model Validation}

Once optimal parameter values were chosen via the DDS routine, each calibrated model was then run over a new time period. The Gumera model was run from 1992 through 1995, with the first year being used as a model warm-up period. The subsequent three years, were then used as the validation period. Townbrook was modeled from 2002 through 2004, again with the first year being a warm-up year.

\section{Model Evaluation}

Three criteria were used for evaluation of SWAT-CN and SWAT-WB. First, a visual comparison was made between the modeled and the observed hydrographs. The second evaluation tool used was the Nash-Sutcliffe Efficiency (NSE). The NSE ranges from $-\infty$ to 1 and is given by equation 6 :

$$
N S E=1-\frac{\sum_{i=1}^{n}\left(O_{i}-S_{i}\right)^{2}}{\sum_{i=1}^{n}\left(O_{i}-\bar{O}\right)^{2}}
$$

where $O_{i}$ is the observed flow for the $i^{\text {th }}$ day of simulation, $S_{i}$ is the modeled flow for the $i^{\text {th }}$ day of simulation, and $\bar{O}$ is the long term mean of the observed 
flow. A NSE of one indicates that modeled flows perfectly match the observed flows; a NSE of zero indicates that the modeled flows are as good a predictor as simply taking the long term mean; and a negative value for NSE indicates that using the long term average for predicting any given day's flow is more accurate than using the model (Moriasi et al., 2007).

The third model evaluation technique was the coefficient of determination, $R^{2}$, obtained by squaring Pearson's coefficient of correlation, $r$, and given by equation 7 :

$$
R^{2}=\left\{\frac{\sum_{i=1}^{n}\left(O_{i}-\bar{O}\right)\left(S_{i}-\bar{S}\right)}{\left[\sum_{i=1}^{n}\left(O_{i}-\bar{O}\right)^{2}\right]^{0.5}\left[\sum_{i=1}^{n}\left(S_{i}-\bar{S}\right)^{2}\right]^{0.5}}\right\}^{2}
$$

where $O_{i}, S_{i}$, and $\bar{O}$ are the same as for equation 6 , and $\bar{S}$ is the long term mean of the simulated flows. $R^{2}$ varies from zero to one; with values closer to one indicating that the observed data and simulated results correlate linearly (Moriasi et al., 2007).

\section{Model Comparison}

To determine if SWAT-WB was indeed a more accurate version of SWAT, two SWAT-CN models of the Gumera watershed were used as benchmarks. The first SWAT-CN model used was developed for this project in order to compare spatial distribution of runoff within Gumera. This model used the same spatial data as the SWAT-WB model and was subject to the same calibration process (with the exception of calibrating $\mathrm{CN}$ values rather than $E D C$ values). Additionally, model statistics from SWAT-WB were compared to 
a SWAT-CN model of Gumera previously published. Setegn et al. (2008), used a twelve year calibration period, and produced a model with a daily NSE of 0.61 and a $R^{2}$ of 0.71 . Validation results for their model returned a NSE of 0.61 and an $R^{2}$ of 0.70 (Setegn et al., 2008).

SWAT-WB results for Townbrook were compared to results from both unmodified SWAT-CN, and SWAT-VSA. Predicted streamflow for the SWATCN Townbrook model resulted in a daily NSE and $R^{2}$ of 0.43 and 0.59 , respectively, for calibration, and 0.62 and 0.69 , respectively, for validation. SWAT-VSA had a NSE and $R^{2}$ of 0.56 and 0.64 , respectively, during calibration with model results during the validation period of NSE and $R^{2}$ values of 0.68 and 0.74 , respectively (Easton et al., 2008).

\section{Results}

As predicted, SWAT-WB returned more accurate results than SWAT$\mathrm{CN}$ for both Gumera and Townbrook. While neither model performed perfectly in these two watersheds, SWAT-WB was more accurate in modeling discharge at both watershed outlets (based on statistics and visual comparison of hydrographs, Figure 9) than SWAT-CN. Additionally, intrawatershed runoff producing areas were modeled with higher spatial resolution than SWAT-CN due to the inclusion of the STI-based HRU delineation process as introduced in SWAT-VSA. 

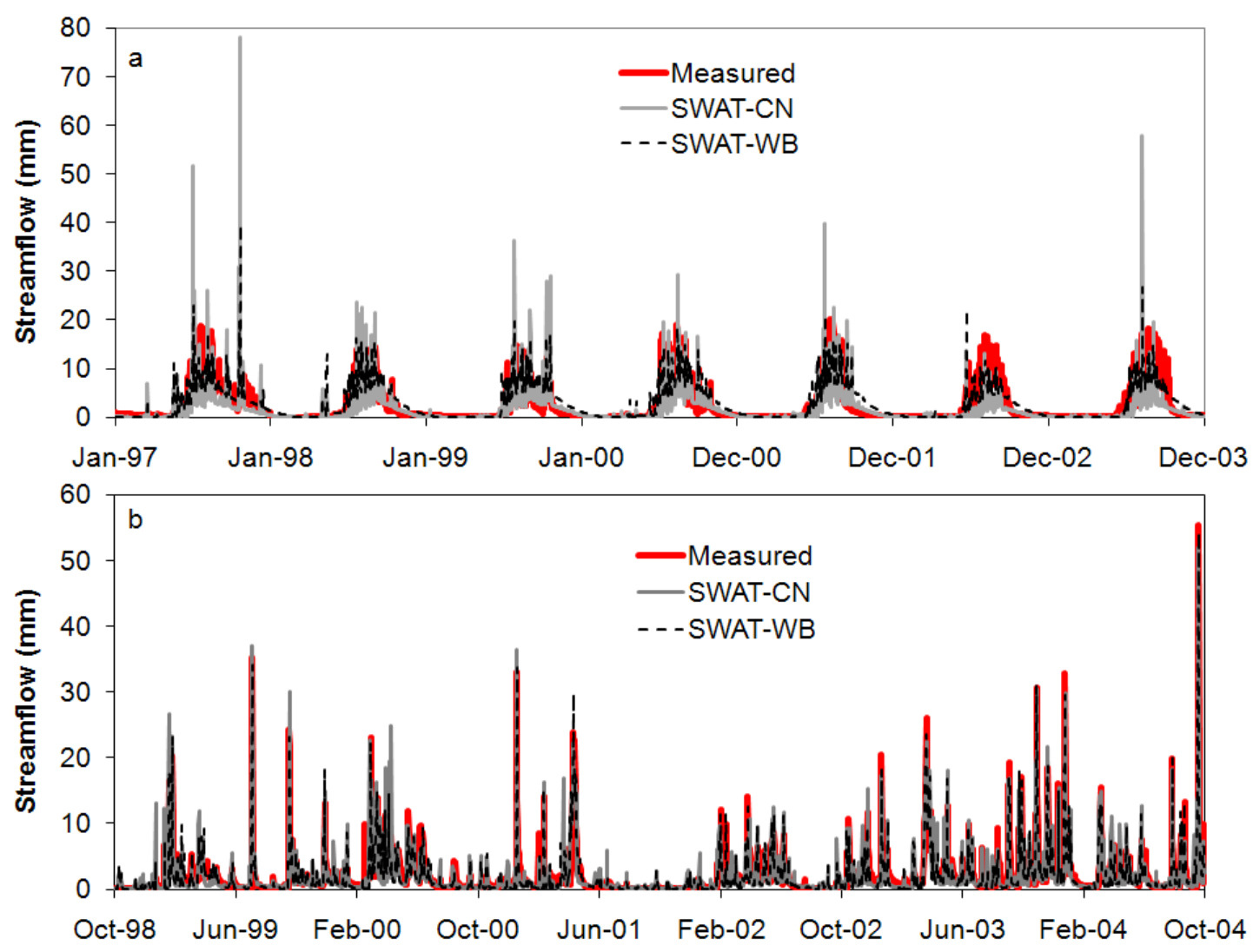

Figure 9. Observed and modeled streamflow for a) Gumera and b)

Townbrook.

\section{Gumera Basin}

Upon calibration of hydrologic parameters using DDS, SWAT-WB returned more accurate results than both of the SWAT-CN models of the Gumera basin. A daily NSE value of 0.70 for the calibration period was achieved, with an $R^{2}$ of 0.71 . SWAT-WB accuracy increased for the validation period, with NSE and $R^{2}$ values of 0.76 and 0.81 , respectively. When compared to model statistics from both SWAT-CN models (Table 1), it is clear that SWAT-WB outperforms the original version of SWAT in Gumera. 
Table 1. Overall model statistics for daily streamflow in Gumera Basin.

\begin{tabular}{c|cc|cc|cc} 
& \multicolumn{2}{|c|}{ SWAT-WB } & \multicolumn{2}{c|}{ SWAT-CN } & \multicolumn{2}{c}{ SWAT-CN $^{\mathbf{2}}$} \\
& Calibration & Validation & Calibration & Validation & Calibration & Validation \\
\hline NSE & 0.70 & 0.76 & 0.64 & 0.67 & 0.61 & 0.61 \\
$\mathbf{R}^{\mathbf{2}}$ & 0.71 & 0.81 & 0.65 & 0.73 & 0.71 & 0.70
\end{tabular}

${ }^{1}$ same input as SWAT-WB

${ }^{2}$ from Setegn et al., 2008

Results for each individual year were, for the most part, similar to those for the entire simulation period. With two exceptions, 1996 and 1999, NSE and $R^{2}$ values fluctuated from being slightly lower than the long term values to being slightly larger.

Table 2. Yearly model statistics for daily streamflow in Gumera Basin, as modeled with SWAT-WB.

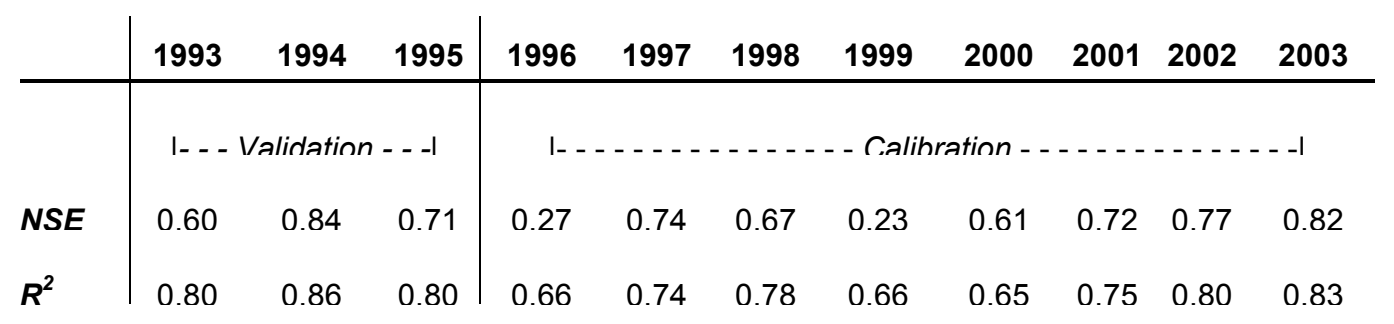




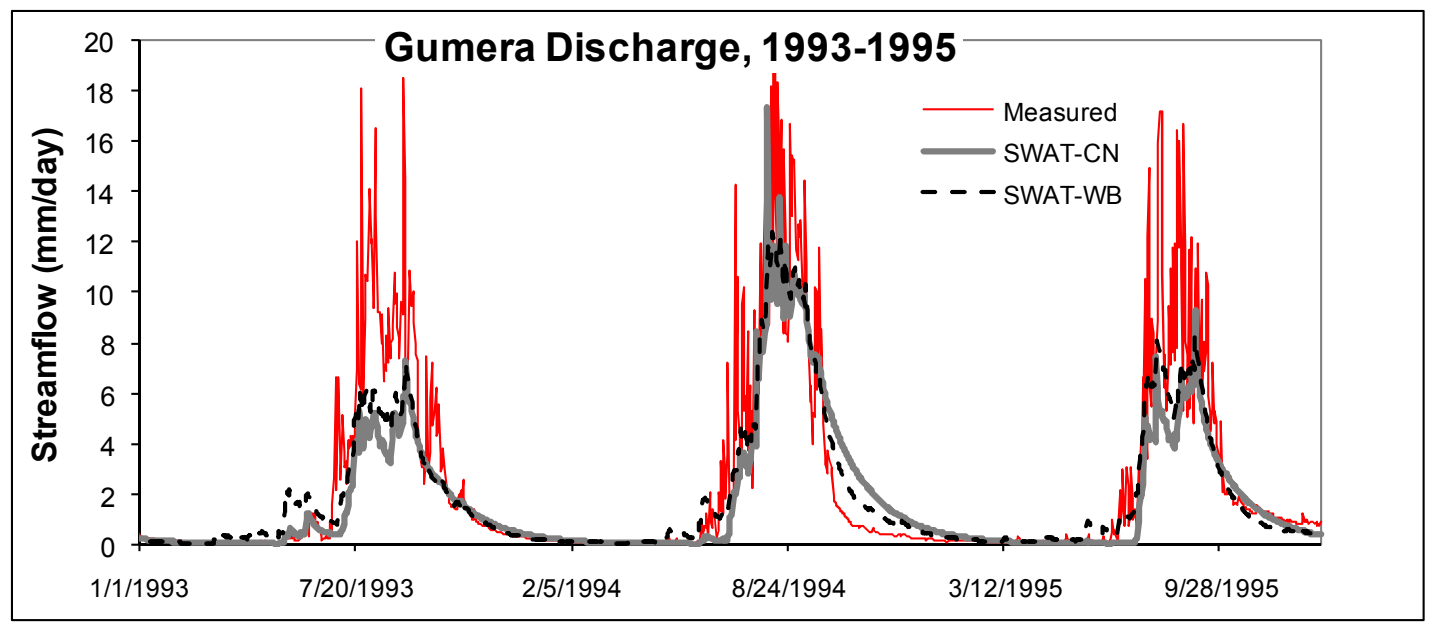

Figure 10. Observed and modeled hydrograph for Gumera during validation period.

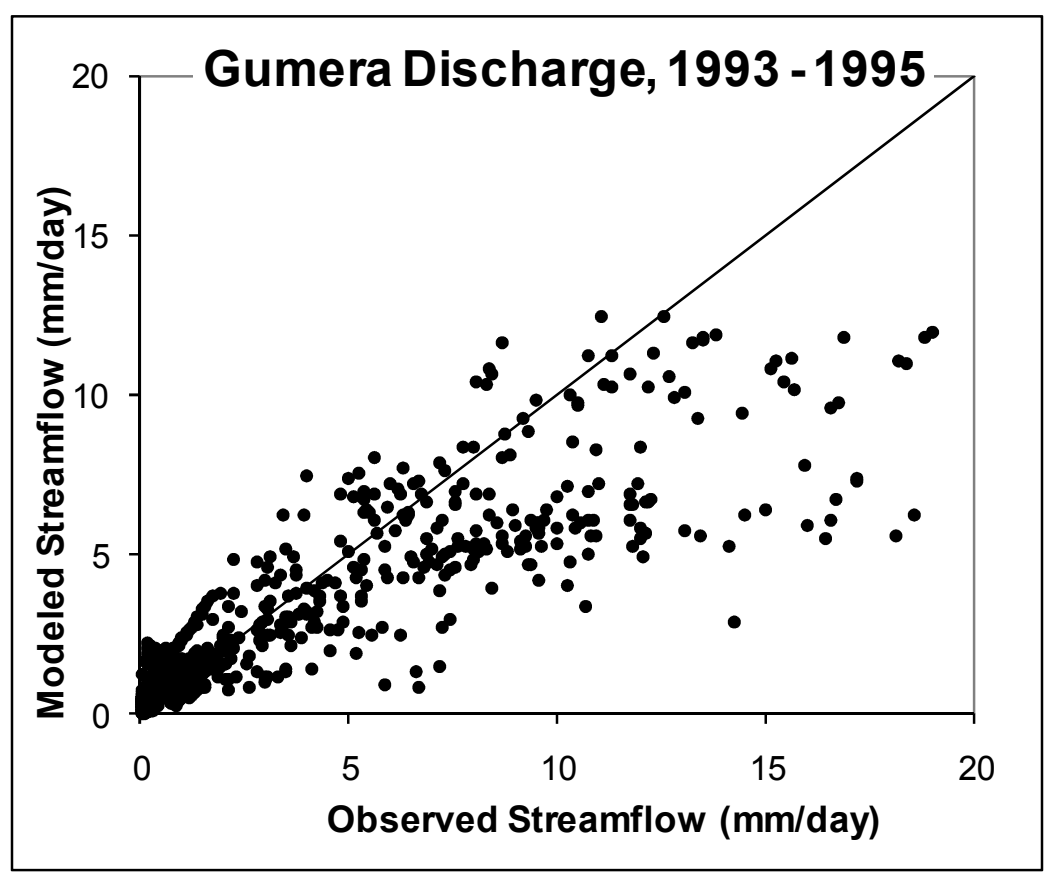

Figure 11. SWAT-WB modeled streamflow versus observed streamflow for Gumera, during valdiation period. 
As predicted, SWAT-WB distributes runoff generation much differently than the $\mathrm{CN}$-based model. For one large storm, SWAT-CN predicted that all HRUs within the watershed would contribute runoff; with a minimum depth of $17 \mathrm{~mm}$ of runoff and a maximum of $71 \mathrm{~mm}$ (Figure 13A). Contrarily, SWATWB predicted, for the same storm, that some HRUs would produce no runoff, while others produced as much as $97 \mathrm{~mm}$ of runoff (Figure 13B). Both models predicted higher surface runoff volumes for some upland areas, but SWAT-CN predicted much less runoff being generated in the low-lying, flatter areas near the watershed outlet.

It is important to point out that while SWAT-WB modeled some areas with significantly more surface runoff (97 mm compared to SWAT-CN's 71 $\mathrm{mm}$ ), the total runoff volume for the watershed was less than that of SWATCN's for the single storm event shown in Figure 12. This resulted in SWATWB's daily streamflow prediction being half the magnitude of SWAT-CN's prediction. While both models still overpredicted streamflow, the removal of the $\mathrm{CN}$ reduced the model error for this particular event. 


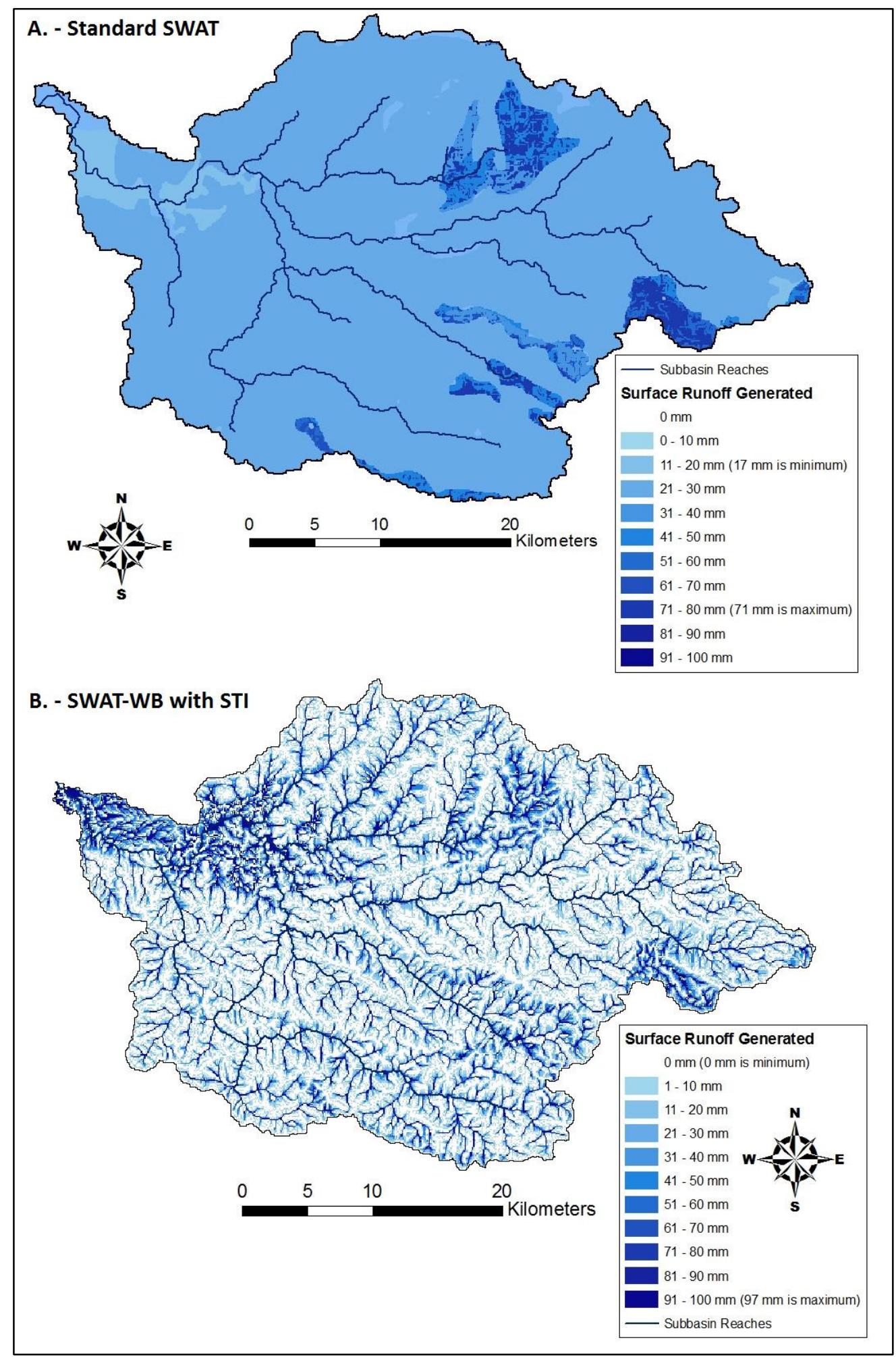

Figure 12. Spatial distribution of surface runoff in Gumera modeled by:

A) SWAT-CN and B) SWAT-WB. 


\section{Townbrook Watershed}

In the Townbrook watershed, SWAT-WB outperformed both SWATVSA and SWAT-CN during the calibration period. However, SWAT-WB's validation period was not as accurate as its calibration period, while both $\mathrm{CN}$ based models performed better during validation. A visual comparison of SWAT-WB's hydrograph with the measured hydrograph (Figure 9) indicates that the model performs fairly well for the Townbrook watershed, a fact supported by the reasonably high daily NSE values (Table 3).

Table 3. Overall model statistics for daily streamflow in Townbrook.

\begin{tabular}{l|cc|cc|cc} 
& \multicolumn{2}{|c|}{ SWAT-WB } & \multicolumn{2}{c|}{ SWAT-VSA } & \multicolumn{2}{c}{ SWAT-CN } \\
& Calibration & Validation & Calibration & Validation & Calibration & Validation \\
\hline NSE & 0.64 & 0.52 & 0.56 & 0.68 & 0.43 & 0.62 \\
$\mathbf{R}^{2}$ & 0.69 & 0.65 & 0.64 & 0.74 & 0.59 & 0.69
\end{tabular}

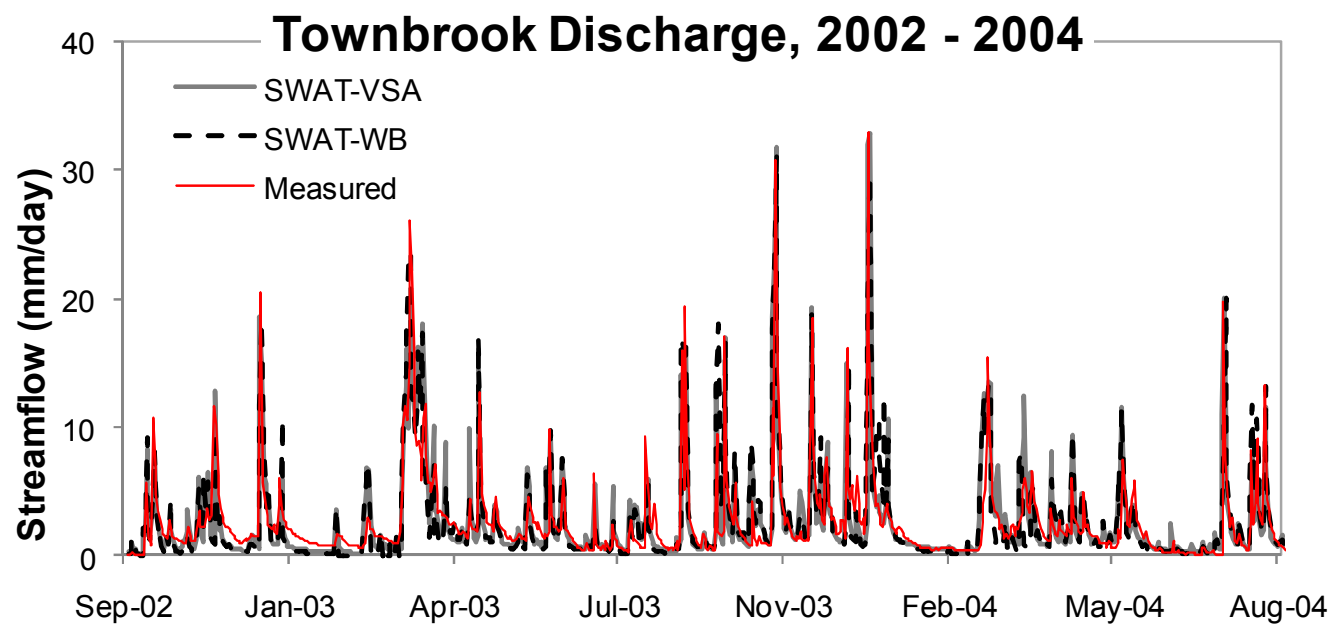

Figure 13. Observed and modeled hydrograph for Townbrook during the validation period. 
Similar to the Gumera results, differences in spatial distribution of runoff is evident when the same event from November 2003 is compared between all three Townbrook models (Figures 14A, 14B, \& 14C). As expected, SWAT-CN predicts surface runoff from the majority of the watershed, whereas both STIbased versions of SWAT estimate that substantial portions of the watershed will generate no surface runoff. There was not much difference in the runoff distribution between SWAT-WB and SWAT-VSA (Figures 14A \& 14B), a fact that is not surprising considering the emphasis both models place on topographic position as it pertains to runoff generation. The volume of surface runoff produced in each wetness class, however, did vary between the two models; maximum surface runoff volume was slightly less for SWAT-WB than for SWAT-VSA. SWAT-WB also predicted that more of the wetness classes would be saturated at the start of this event, leading to the low-lying wet areas producing nearly identical volumes of runoff (i.e. almost the entire volume of precipitation). 


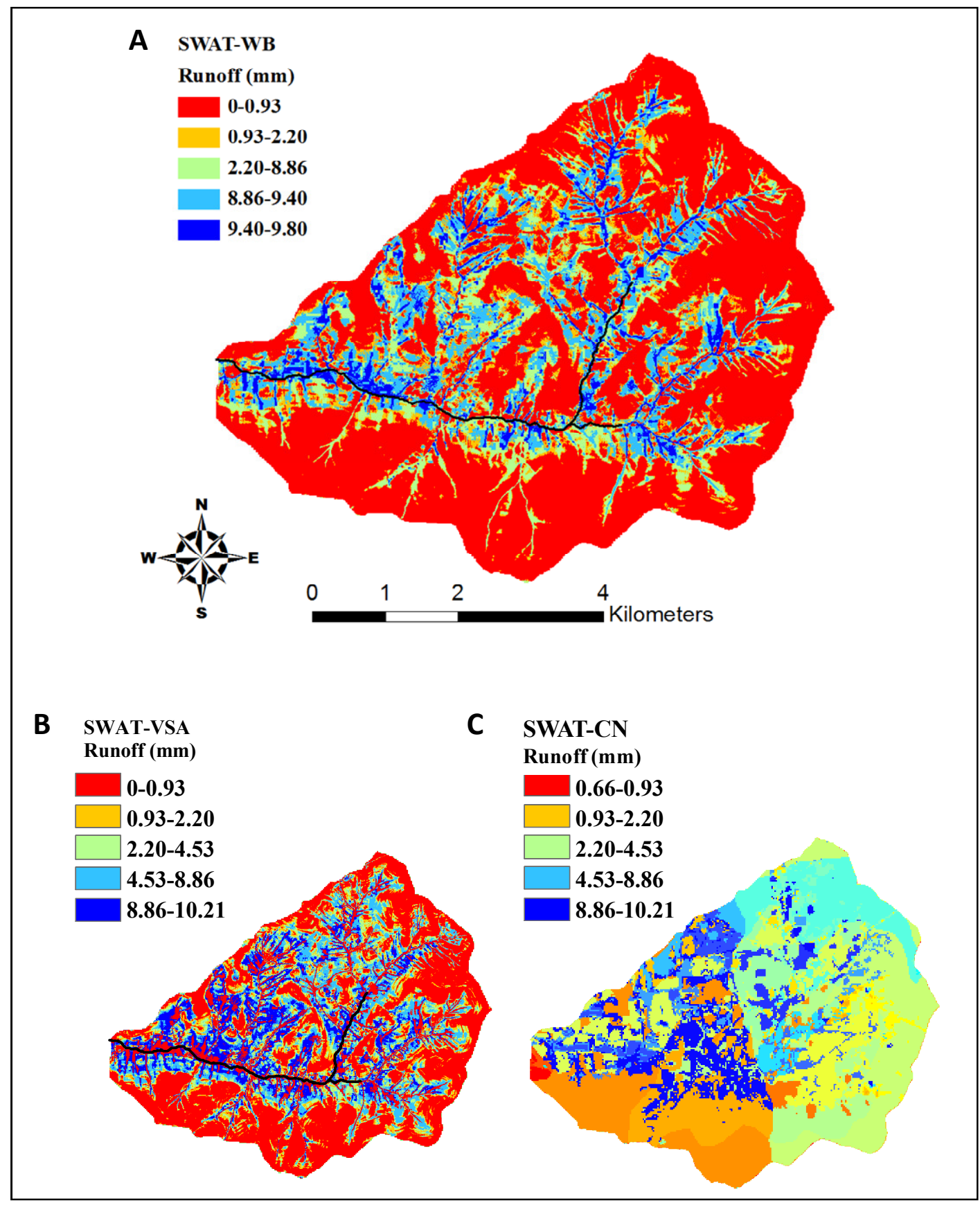

Figure 14. Spatial distribution of surface runoff in Townbrook modeled by: A) SWAT-WB, B) SWAT-VSA, and C) SWAT-CN. 


\section{Discussion}

As expected, SWAT-WB returns more accurate results than SWAT-CN when used to model the monsoonal Blue Nile watershed in Ethiopia. When applied to the Townbrook watershed in the Catskills, the water balance routine was as accurate as a modified $\mathrm{CN}$ method, but more accurate than the original $\mathrm{CN}$ approach.

The CN was easily removed from SWAT; however the need to include another calibration parameter became evident when the saturation deficit for each soil profile was first calculated. If the entire soil profile was included in the calculation of the available storage, $T$, the model did not simulate any surface runoff, all precipitation infiltrated. If only the uppermost soil horizon were used to determine $T$, then essentially all precipitation would runoff, resulting in no infiltration. By examining a range of soil depths used to calculate $T$, it became clear that the total depth used to determine surface runoff had to be adjusted; hence the introduction of $E D C$, the effective depth coefficient.

The issue of these water balance inaccuracies prior to inclusion of EDC is nothing new. Many previous water balance models of the Blue Nile were limited to application at a monthly timestep due to inabilities to successfully partition between baseflow, interflow, and surface runoff (Johnson and Curtis,1994; Conway, 1997). When no EDC was used in SWAT-WB, these same issues were present; high t values resulted in only baseflow simulation, and when $\mathrm{T}$ was too high, all precipitation became surface runoff with minimal baseflow contributions.

Interestingly, the EDC solution to these issues is remarkably similar to a recent water balance model developed for the Blue Nile which combined a water balance with a traditional tank model. To differentiate between surface 
and various subsurface flows, Kim and Kaluarachchi (2008) developed a model using two tanks. The upper tank, described by an "upper zone soil moisture" term was used to calculate surface runoff, and a "lower zone soil" was used to capture baseflow dynamics. The upper layer would produce no surface runoff until a "runoff orifice" depth was filled by rainfall. This upper zone soil layer with its runoff orifice depth is analogous to SWAT-WB's EDC term; both parameters acknowledge that only a certain portion of the soil profile plays a role in runoff generation.

While Kim and Kaluarachchi, (2008) used a lower soil zone tank to model baseflow, no such layer was required for SWAT-WB. The original SWAT program already models baseflow using soil moisture calculations for the entire soil profile, and no changes were required after EDC was introduced in SWAT-WB. While different EDC values will lead to different surface runoff values, and subsequently different infiltrated volumes, no other changes to the baseflow routines were made. Therefore EDC determines a depth analogous to Kim and Kaluarachchi's upper zone soil layer, but it does not assign a lower zone layer. Rather, SWAT's included baseflow routines are used for all infiltrated water throughout the entire soil profile.

Clear improvements were made to SWAT in the Ethiopian watershed by removal of the $\mathrm{CN}$, however the results are not as definitive for the Townbrook watershed in New York State. While SWAT-WB has substantially higher model statistics for the calibration period, it does not perform as well during validation as SWAT-CN and the modified CN-based SWAT-VSA.

By comparing the hydrograph from Townbrook's outlet (Figure 14) and the somewhat ambiguous model statistics, it appears that SWAT-WB performs at least as well as SWAT-VSA and SWAT-CN. The fact that there was not as 
big of a difference between these models in New York State is also likely a result of the more evenly distributed precipitation throughout the year. As noted above, CN models were developed mainly in the US where precipitation is generally more evenly distributed than in other, monsoonal regions of the world. As such, an empirical relationship, such as the $\mathrm{CN}$, will tend to capture these trends well. The water balance model is able to perform as well here due to rainfall intensities in the Townbrook watershed that are generally less than the soil infiltration rate (Walter et al., 2003). Thus runoff is created when the soil profile becomes saturated, a situation that the water balance model was developed to capture.

SWAT-WB is capable of predicting runoff generating areas better than SWAT-CN due to the inclusion of STIs. Previously, the location within each subbasin of HRUs was not given much care. Any location that shared landuse and soil was considered an $\mathrm{HRU}$, regardless of its topographic position and the corresponding likelihood to produce runoff. In SWAT-WB, STIs were used to link HRUs by similar topographic position, giving model users the capability to examine intra-watershed runoff dynamics.

This improved determination of runoff generating areas is clearly demonstrated for both watersheds in Figure 12 and Figure 14. For the same large storm event in the Gumera basin (Figure 12), SWAT-WB did not generate surface runoff for all HRUs, whereas SWAT-CN predicted that the entire watershed would contribute surface runoff. Holding with principles of VSA hydrology, SWAT-WB predicted that the wettest portions of the watershed would contribute more runoff than as predicted by SWAT-CN. Additionally, in SWAT-WB the driest areas produce no runoff, while SWAT-CN still models runoff from these areas. 
In addition to the fact that SWAT-CN predicts a nearly uniform runoff volume for the entire watershed, there are two other points of interest that should be discussed. First, is the fact that SWAT-CN predicts that the area nearest Gumera's outlet produces the least amount of surface runoff. This is exactly opposite of SWAT-WB's results which predict that this area produces the highest runoff volumes. These differences between the models can easily be explained by the inclusion of slope in the HRU delineation (and therefore EDC calibration). Again, holding with VSA principles, SWAT-WB assumes that these flat, near-stream regions will wet up and contribute the most runoff, whereas SWAT-CN treats these HRUs the same as any upland region with the same soil and land cover. The second interesting point is that both models predict that certain upland regions will be generating a significant portion of surface runoff from this storm.

The fact that both SWAT-CN and SWAT-WB predict higher surface runoff volumes in certain upland areas can be attributed to two factors: soil type and slope. Upland areas in Figure 12A that contribute higher volumes of surface runoff (>30 mm) spatially correspond to areas with a eutric leptosol soil (Figure 15). This soil has significantly lower saturated hydraulic conductivities, $K_{s}$, than the other soils in Gumera, which led to high daily CNs being calculated by SWAT-CN. This, in turn, resulted in more runoff being generated for HRUs with a eutric leptosol than for those with different soils. These lower $K_{s}$ values for eutric leptosol also played a role in runoff generation in SWAT-WB. $K_{s}$ appears in the denominator of the STI (equation 5), which will cause higher $S T I$ values to be calculated when lower $K_{S}$ are assigned. Therefore these areas with a eutric leptosol have higher STI values, resulting in SWAT-WB predicting more surface runoff generation, just as SWAT-CN did. 


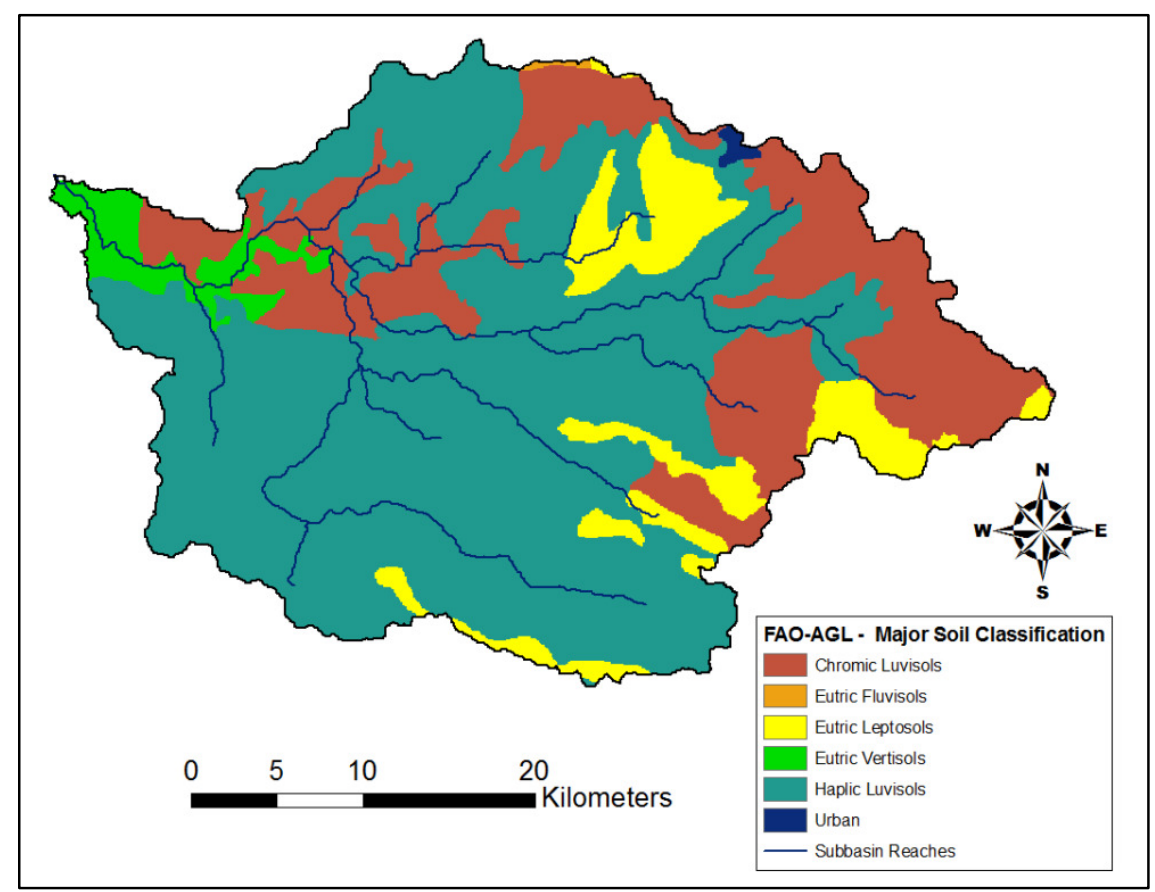

Figure 15. Major soil types in the Gumera basin.

Where low $K_{s}$ values for eutric leptosols resulted in more surface runoff for both models, SWAT-WB's runoff prediction for these areas was also controlled partially by topographic slope. The areas with eutric leptosols also had lower than average slope values (Figure 16). Just as lower $K_{s}$ values increased the STI value, lower slope values will do the same. Both of these lower-than-average values produce a STI that is noticeably higher than other locations with a similar contributing area (Figure 4). Calibration of EDC independently for each wetness class (as defined by $S T I$ ), allows for SWATWB to capture these anomalous runoff contributing areas just as SWAT-CN did. 


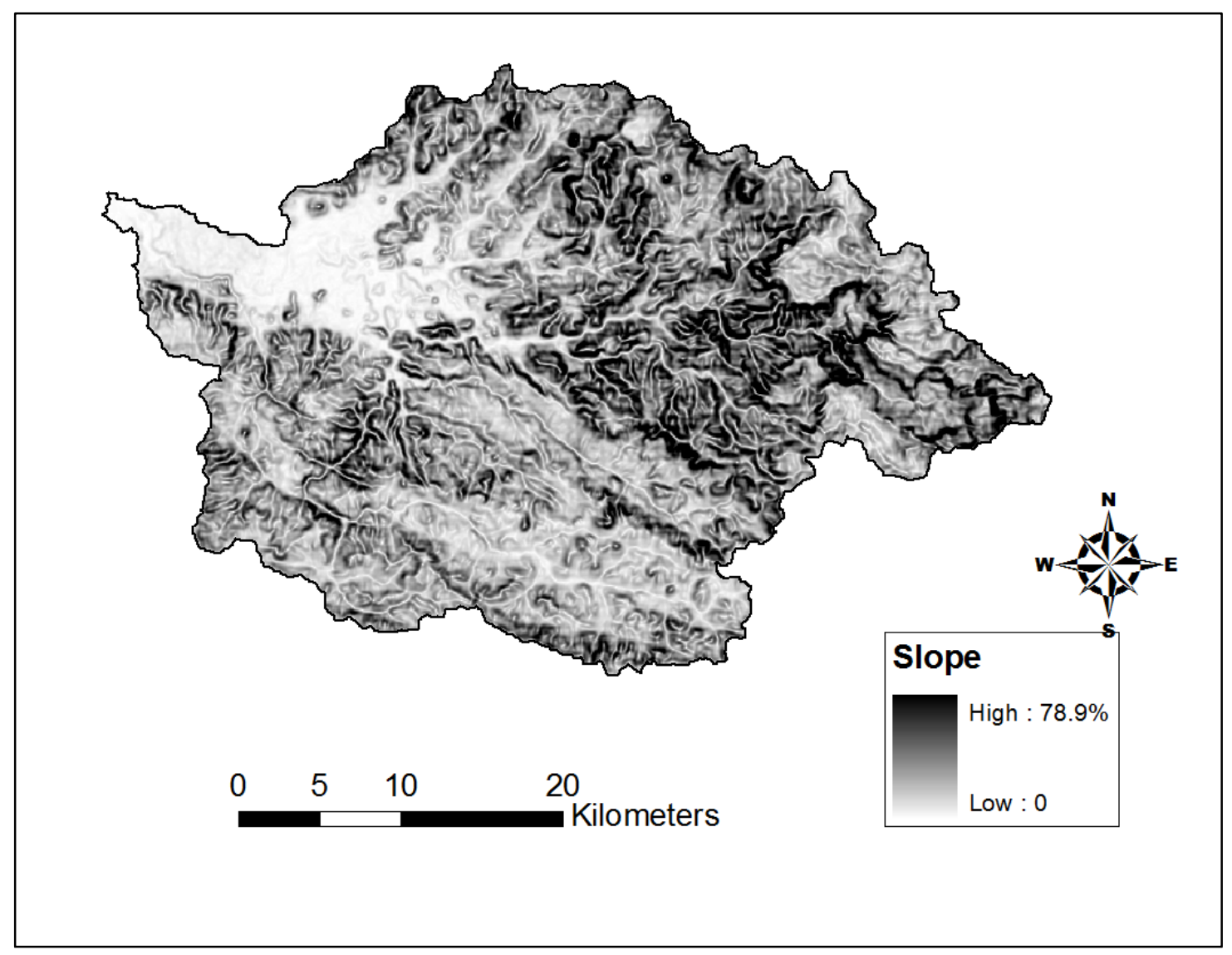

Figure 16. Slopes in the Gumera basin.

SWAT-CN and most other watershed models have been developed for temperate climates where rainfall is generally well distributed throughout the year. Running models developed in a temperate climate for Ethiopia conditions, with a monsoonal climate, is problematic. Temperate models assume that there is a nearly unique relationship between precipitation amounts or intensity and runoff generated. This is not the case for Ethiopia as demonstration by the results of Liu et al. (2008) where for three watersheds with more than 16 years of record, the rainfall relationship was far from unique. The first rains after the dry season all infiltrate and nearly no runoff is generated. As the rainfall season progresses more and more rainfall becomes 
runoff. Since the intensity of the rain did not affect the runoff amounts for a given storm, the runoff mechanism is saturation excess runoff (Liu et al., 2008).

Water balance models are consistent with saturation excess runoff process because the runoff is related to the available watershed storage capacity and the amount of precipitation. The implementation of water balances into runoff calculations in the Blue Nile basin is not a novel concept and often performs better (as did our results) than more complicated models in Ethiopia type landscapes (Johnson and Curtis, 1994; Conway, 1997; Ayenew and Gebreegziabher, 2006; and Liu et al., 2008). These water balance models are typically computed with monthly or yearly values because the models are generally not capable of separating base- inter- and surface runoff flow. However, to truly model erosion and sediment transport, large events must be captured by the model and daily simulations are required to do so. Thus SWAT-WB not only maintains a water balance but also calculates the interflow and the base flow component and also gives a reasonable prediction of peak flows. SWAT-WB is therefore more likely to capture sediment transport than either SWAT-CN or water budget models with monthly time steps. Note that by choosing to run models on a daily time step, the model performance always is significantly worse than for monthly or yearly time steps.

SWAT-WB is more in tune with the runoff processes that occur in the Ethiopian highlands than other models that base their runoff prediction on the NRCS curve number method. The calculations that serve as a foundation for NRCS curve number technique assume that the moisture condition in the soil can be determined by taking into account the five day previous rainfall events. As indicated above, the moisture content in monsoonal climates is changing 
during the first $500 \mathrm{~mm}$ of effective precipitation, or approximately 1-2 months. SWAT-WB, on the other hand, determines runoff volume simply by calculating the available storage in each soil profile. This value is not dependent only upon the five previous days' rainfall (as the $\mathrm{CN}$ method is), but instead allows for progressive saturation as the rainy season continues.

\section{Conclusion}

Daily modeling of stream flow and surface runoff in a monsoonal watershed was substantially improved by replacement of the $\mathrm{CN}$ method with a simplified water balance routine in the SWAT watershed model. The new water balance routine performed as well in predicting discharge at the outlet as the $\mathrm{CN}$ method in a watershed which experiences evenly distributed rainfall throughout the year. The new version of SWAT, SWAT-WB, uses calculated saturation-deficit values with an effective depth coefficient, $E D C$, to determine what portion of a day's rainfall will enter the stream channel as surface runoff, due to saturation excess runoff processes. This $E D C$-based water balance method is analogous to other tank models that have been successfully applied in regions where the $\mathrm{CN}$ method should not be used.

Furthermore, intra-watershed spatial runoff dynamics are better captured in both watersheds with SWAT-WB due to the inclusion of wetness classes in hydrologic response unit delineation within the SWAT interface. Spatial dynamics were then captured better by calibrating the new EDC parameter independently for each wetness class.

These results indicate that SWAT performs better in saturation-excess controlled areas when a simple saturation-deficit is used to calculate runoff volumes. Hydrologic simulation with SWAT-WB will lead to more accurate 
results in the various regions of the world where SWAT is being applied with increasing frequency and where use of the $\mathrm{CN}$ method is questionable. With a more reasonable, easy-to-use model, effective water and land management schemes will be easier to successfully implement in data-poor regions of the world. 


\section{APPENDIX}

This Appendix contains material which was developed to make SWATWB available to the public in an understandable and easy-to-use manner. All of this information will be posted on the website for Cornell University's Soil and Water Lab. From this website interested users will be able to download: the executable file used to run SWAT-WB simulations, documentation on the model, a User's Manual, and sample files which will serve as a template for files that must be created by the user before SWAT-WB can be run. 


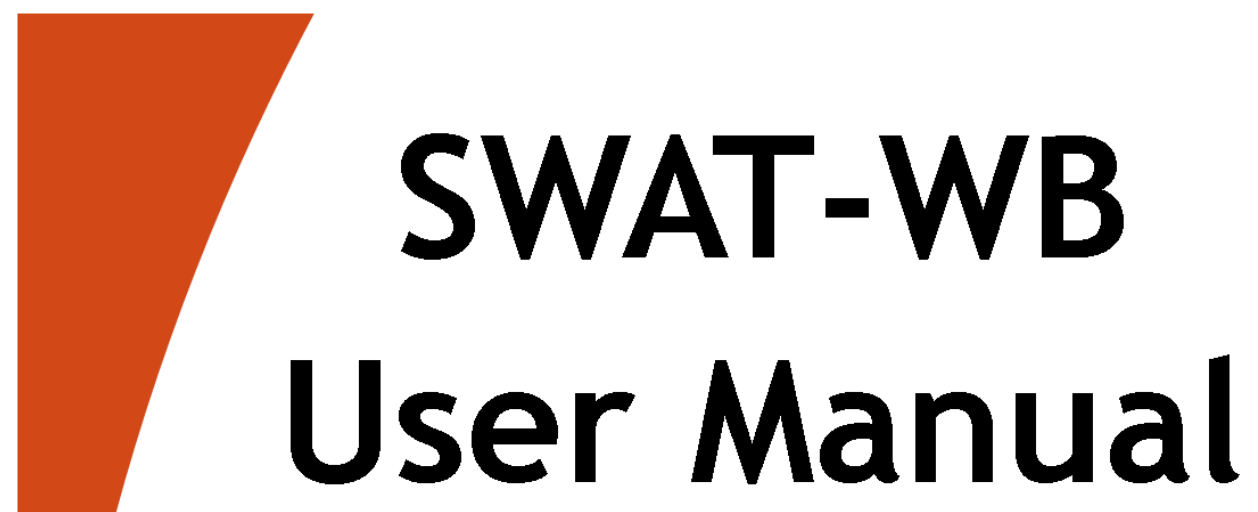

Eric D. White

Zach M. Easton

Dan R. Fuka

Tammo S. Steenhuis

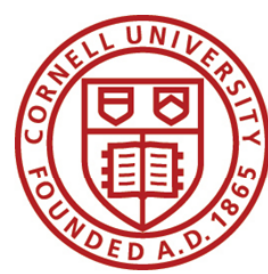

(c) 2009

Soil and Water Lab

Dept. of Biological and Environmental Engineering

Cornell University

Ithaca, NY 
SWAT-WB is a modified version of the Soil \& Water Assessment Tool, which was developed with the explicit goal of accurately modeling surface runoff generation without using the USDA-NRCS Curve Number (CN) method. Instead of using the CN method, a physically based soil water balance (WB is short for water balance) is used for every day of simulation. This results in a version of SWAT which models runoff generated strictly from saturationexcess processes; no surface runoff will be generated with SWAT-WB until the soil becomes sufficiently saturated. Therefore, this version of SWAT is intended for use in watersheds where either the user wishes to model runoff without relying upon the $\mathrm{CN}$, or in watersheds where saturation-excess is the predominant mechanism for runoff generation.

This model was designed to replace the CN-based SWAT 2005, and can be used by making a few simple adjustments to any preexisting SWAT2005 project; detailed descriptions of these adjustments are provided below.

\section{Create a SWAT project}

Before SWAT-WB can be used, a standard SWAT project must be created. There are multiple ways to accomplish this step, the simplest of which is to use a GIS interface. Users can download extensions for both ArcGIS and for MapWindow (a free, open source GIS) which will create the files necessary to run SWAT and SWAT-WB. If the user is not comfortable with using GIS, a more labor intensive process can be followed to develop the necessary text input files (as described in the SWAT Input/Output File Documentation available from the official SWAT website).

During the project development stage, follow all steps as outlined in the official SWAT manual, up to and including the writing (and editing, if so desired) of the input files.

When soils data is added and reclassified during the HRU Analysis portion, make a point of recording each soil type's name that is assigned by SWAT. These recorded soil names will be used in a later step.

After the input files are written, expand the SWAT Simulation menu and select the Run SWAT button (Figure 1). 


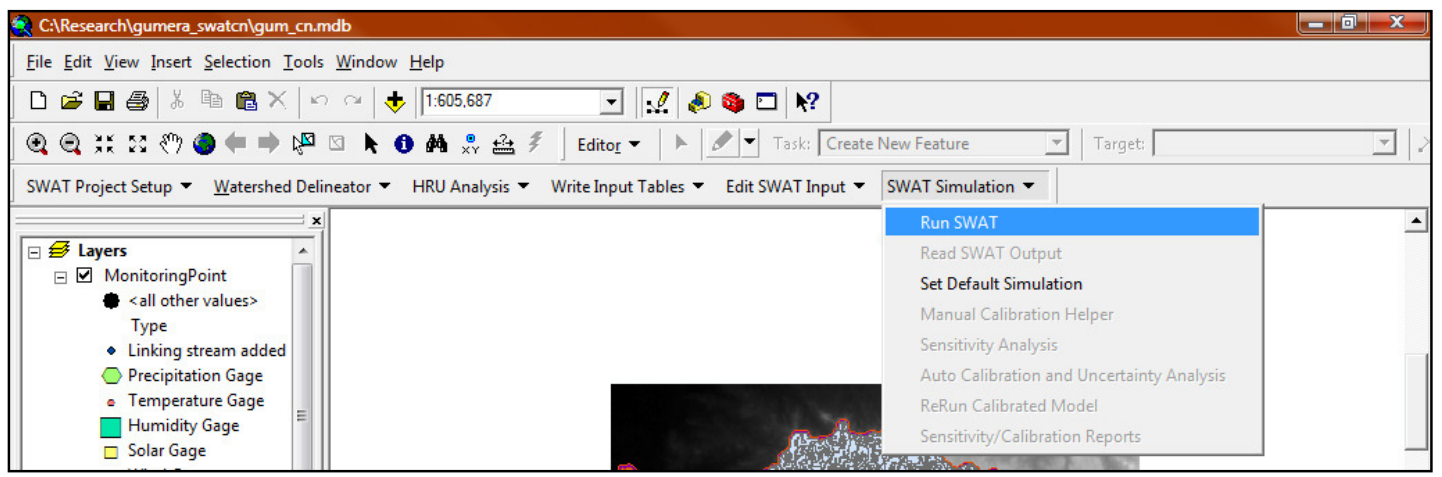

Figure 17. After all input files are written in the GIS interface, select the Run SWAT button.

In the Setup and Run SWAT Model Simulation window, set the final parameters for the model run and click the Setup SWAT Run button (Figure 2), which will create one final input file called file.cio. At this point, the project setup is complete (Figure 3 ) and if the user were to click the Run SWAT button, the simulation would be run using SWAT2005. However, if the user wants to use SWAT-WB, a few modifications must first be made to the project outside of the GIS interface.

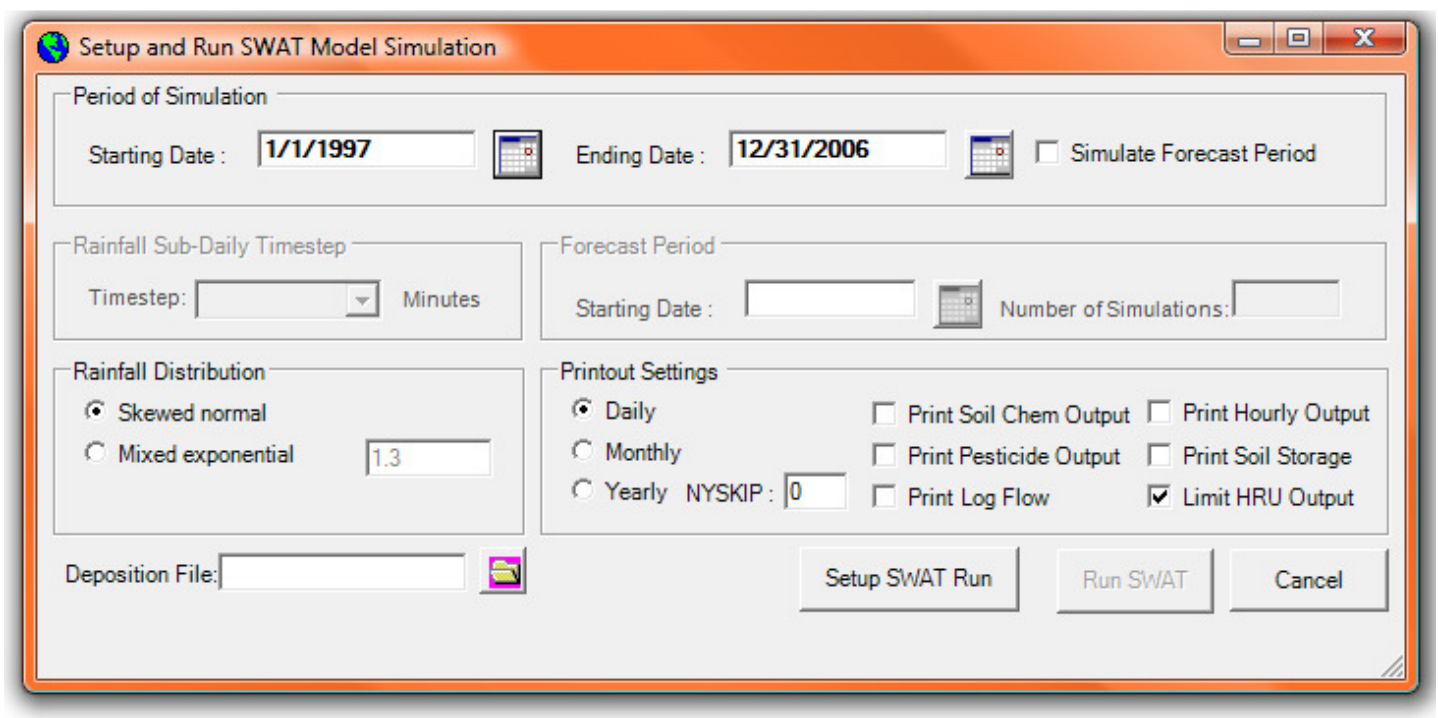

Figure 18. Set final parameters and click Setup SWAT Run. 


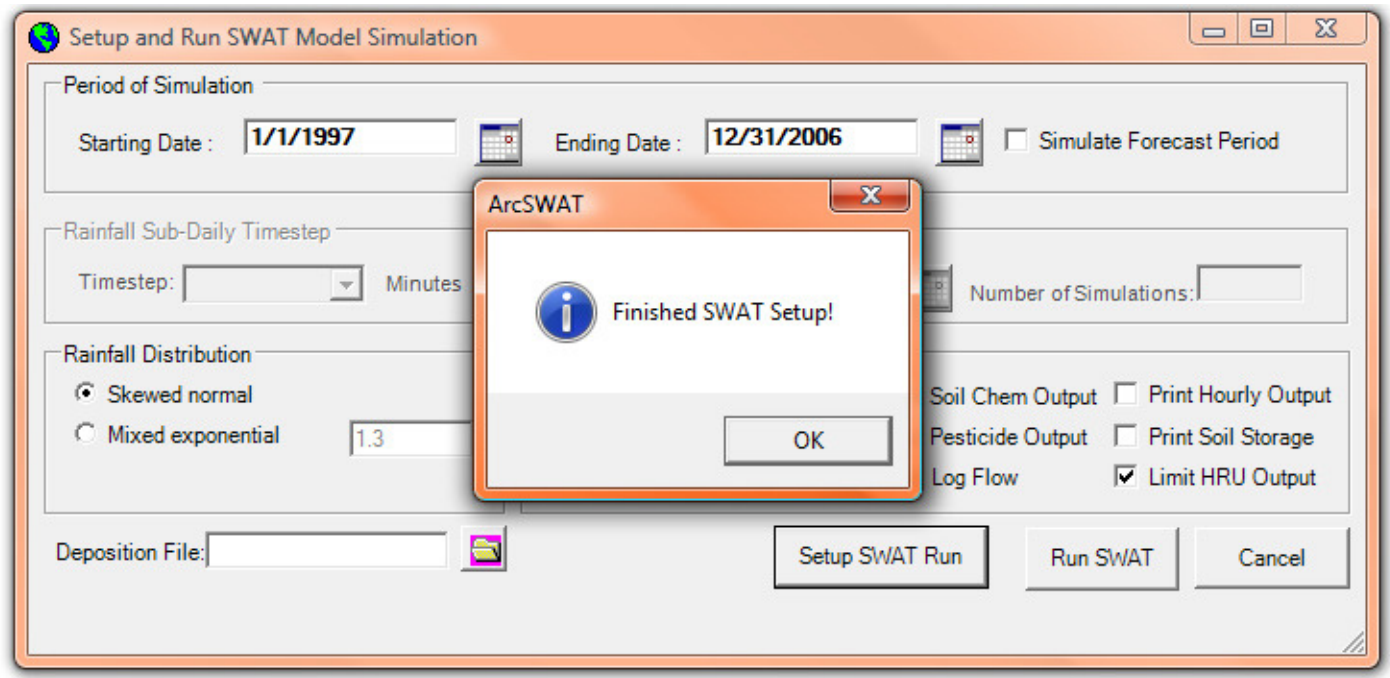

Figure 19. After clicking Setup SWAT Run, the project is ready to be modified for use with SWAT-WB.

\section{Add files to the project folder}

After the project setup is complete, copies of two files must be placed in the project folder which is the location on the user's computer where all of the text input files were saved (Figure 4). The folder name is TxtInOut and is located at: ... Iprojectdirectory|Scenarios|Default, where projectdirectory is the name of the folder created in the first step of the SWAT GIS interface.

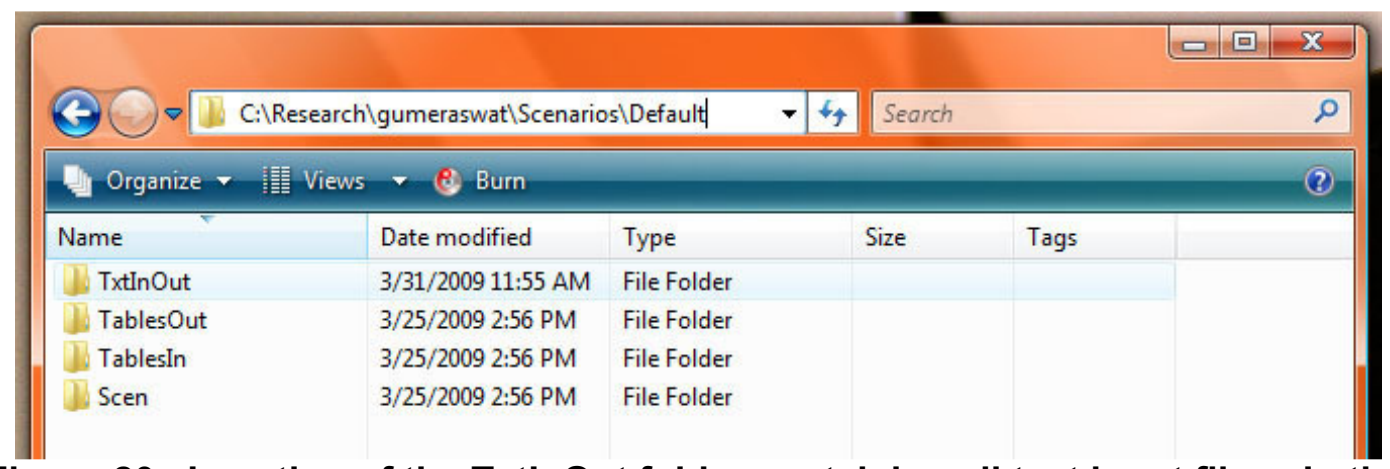

Figure 20. Location of the TxtInOut folder containing all text input files. In the above figure, C:IResearchlgumeraswat will be replaced by the location of the specific project directory created during the project setup.

Before files are copied to the TxtInOut folder and the project is modified to work with SWAT-WB, the user may want to copy the entire TxtInOut folder and save it in a different location on their computer. All modifications to the text files should be done to the TxtInOut copy, rather than the original folder. This will ensure that the files developed 
with the GIS interface remain unchanged; the user can then redo these steps, or revert to the default SWAT2005 program, at anytime without having to start over at the beginning of the GIS interface.

\begin{tabular}{|l|l|l|l|l|}
\hline \multicolumn{1}{|c|}{} \\
\hline Name
\end{tabular}

Figure 21. The TxtInOut folder containing the input files developed during the project setup stage.

Once the TxtInOut folder has been located and copied to a new location, two files need to be added to this folder. Soilname.bee and swatwb.exe files were downloaded from the SWAT-WB website and are located in the same swatwb.zip file that contains this manual. These two files need to be placed in the TxtInOut folder.

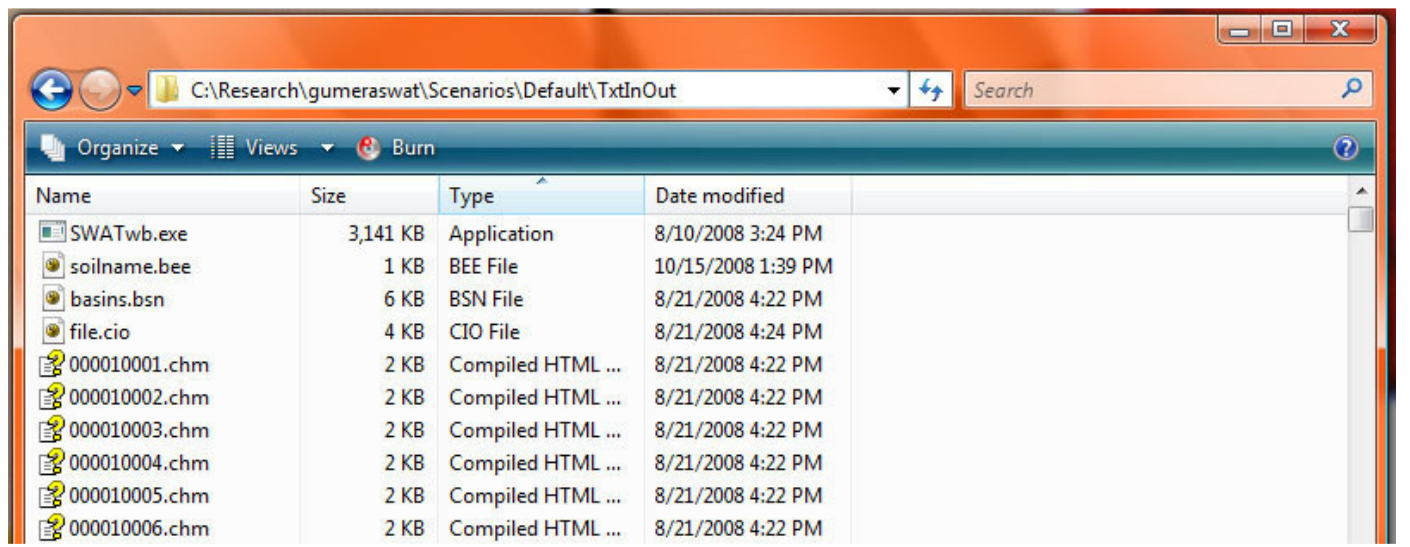

Figure 22. The TxtInOut folder containing the files needed to run SWAT-WB.

\section{Create new .bee files}

Once the original soilname.bee file has been added to the TxtInOut folder, it should be used as a template to create a similar .bee file for each soil present in the watershed (i.e. if the watershed being modeled has five soil types used in the HRU definition process, than five separate .bee files need to be created). Replace the 'soilname' in each file's name with the SWAT-assigned name (these were recorded during 
the first step) for each soil type in the watershed (i.e. a soil named Hudson, will have a file named Hudson.bee).

These .bee files contain a single variable, $E D C$, which ranges from 0.000 to 1.000 . For lower EDC values, less water will infiltrate the soil profile during a rain event, resulting in more surface runoff.

\section{A full discussion of the EDC variable is provided in the Theoretical Documentation and should be consulted when choosing EDC values for each soil type.}

When changing the value of this variable, be sure to adhere to the formatting of the original .bee files; change only the number value in the file and do not change the character spacing of this value (it should occupy spaces $12-16$ on the second line). If an EDC value of 1.000 is chosen, SWAT-WB will use the saturation-deficit of the entire soil profile to calculate the maximum volume of rain able to infiltrate.

\section{Run SWAT-WB}

Once all input files have been created and the .bee files have been created for each soil type, there are two ways to run SWAT-WB. The simplest is to double click swatwb.exe in the TxtInOut folder. This will result in a command window opening which will show the progress of the model simulations. Once the model is done running, this window will close automatically.

The second way to run SWAT-WB doesn't automatically close the command window and is therefore more useful if the model is not running correctly. To run SWAT-WB this way, the executable should be run from a command prompt. To open a command prompt window first open the Start Menu from Windows taskbar. Navigate to All Programs, then to Accessories and click on Command Prompt (Figure 7a), or navigate to Run, type $c m d$ and hit OK (Figure 7b). 




Figure 23. Accessing Windows Command Prompt either from Start Menu>All Programs $>$ Accessories (A) or from the Run tool (B).

In Command Prompt, change the working directory to the TxtInOut folder in which soilname.bee and swatwb.exe files have been saved. To accomplish this, type $c d$ (for 'change directory') followed by a space and then the entire file path for the swatwb.exe file located in the TxtInOut folder (Figure 8). Hit enter and SWAT-WB will begin to run.



Figure 24. Navigating to project directory with Command Prompt and running SWAT-WB.

\section{Read SWAT-WB output}

After SWAT-WB has been successfully executed, the output files are ready to be viewed. Since SWAT-WB was run from Command Prompt, 
rather than from the GIS interface, the output must be viewed using a text editor (and input into a spreadsheet) rather than using the GIS interface. The official SWAT Input/Output File Documention should be reviewed for a complete description of all output files.

\section{Calibrating SWAT-WB}

Once the initial model run has been completed, it is important to calibrate the model. There are many processes which can be followed to accomplish this; here we will discuss a few methods that we have found can be easily implemented with SWAT-WB.

Dynamically Dimensioned Search (DDS) Algorithm

DDS is an autocalibration routine developed by Dr. Bryan Tolson (University of Waterloo) and Dr. Christine Shoemaker (Cornell University), primarily for use in watershed models. This algorithm is used outside of the GIS interface and can be downloaded in various formats. The MATLAB version of DDS has been successfully used to autocalibrate two different SWAT-WB models. DDS and papers describing it can be found from Dr. Tolson's website: www.civil.uwaterloo.ca/btolson/software.htm.

\section{PARASOL}

PARASOL is an autocalibration algorithm included in the SWAT program and available for use within the GIS interface. Using PARASOL requires the user to rename swatwb.exe to swat2005.exe and replacing the original swat2005.exe file found in the default SWAT installation folder (normally found in C:IProgram Files). At this point the GIS interface will run SWAT-WB rather than the original SWAT program, and the included autocalibration routine, PARASOL, can then be used. However, the autocalibration files created by the interface must be altered to insure that $E D C$ is a calibration parameter rather than the Curve Number.

\section{Manual Calibration}

Another option, if the user is not comfortable with either MATLAB or with altering files used by PARASOL, is manual calibration.

This concludes the instructions for how to use SWAT-WB. If any problems arise throughout the process listed above, first determine if it is a problem with the default SWAT files, or if it is from SWAT-WB. If it is the former, please refer to either the official SWAT help documentation or the online User Forums. If the problem is determined to be from SWAT-WB please contact someone from the Soil and Water Lab via the contact information provided on the SWAT-WB website. 


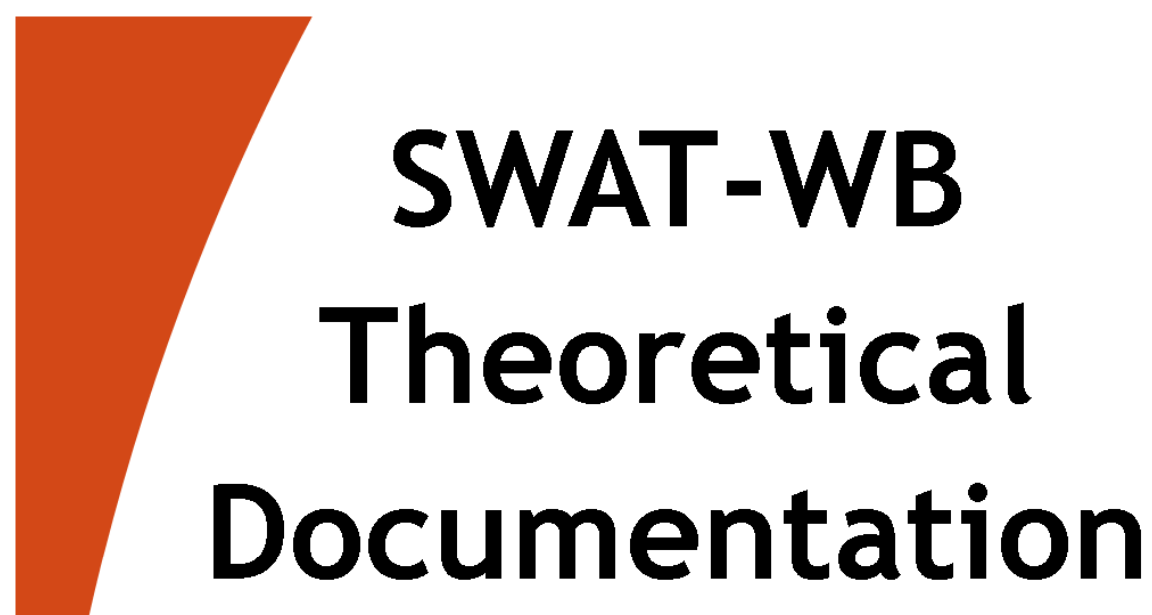

Eric D. White

Zach M. Easton

Dan R. Fuka

Tammo S. Steenhuis

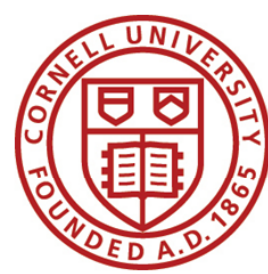

(C) 2009

Soil and Water Lab

Dept. of Biological and Environmental Engineering

Cornell University

Ithaca, NY 
To improve SWAT performance in areas dominated by saturation-excess runoff processes, a new runoff routine was added to SWAT. A daily soil water balance was used to determine the saturation deficit of each hydrologic response unit (HRU) in SWAT, which was then used, instead of the CN method, to determine daily runoff volume. What follows is a brief discussion of the methods used by the original SWAT model, SWAT2005, and the routine that we developed for use in modeling saturation-excess derived surface runoff in SWAT-WB.

\section{Summarized SWAT Description}

SWAT is a basin-scale model designed to simulate hydrologic processes, nutrient cycling, and sediment transport throughout a watershed. Catchment area varies widely throughout the peer-reviewed literature, with SWAT being used on watersheds as small as $0.15 \mathrm{~km}^{2}$ and as large as $491,700 \mathrm{~km}^{2}$ (Gassman et al., 2007). From a digital elevation model (DEM), the watershed will be divided into subbasins that are assigned a stream channel, or reach in SWAT terminology. If the locations of stream gauges are known, the user can choose to have the subbasin outlets correspond to these gauges. Similarly, if a stream network has been previously mapped, this network can be used. If no such data is available, SWAT will determine the stream network from the DEM. All of these processes can be performed via a geographical information system (GIS) interface for SWAT. The ArcSWAT 2.0 interface for ArcGIS 9.2 was used for this project.

For each day of simulation, SWAT models processes such as: rainfall, runoff, infiltration, plant dynamics (including uptake of water and nutrients, biomass, etc.), erosion, nutrient cycling, leaching of pesticides and nutrients, and many others. In addition to the physical processes, users can model scheduled crop rotations, irrigation, fertilizer application, tillage, and harvesting. To increase computing efficiency, SWAT does not distribute these processes throughout the entire watershed. Instead, SWAT models these processes only once for each unique portion of the watershed. To determine these unique areas, SWAT utilizes hydrologic response units (HRUs). Each subbasin of a watershed is divided into HRUs, which are traditionally defined as the coincidence of soil type and landuse. The HRU is the smallest unit in the SWAT model and is used to simulate all of the processes mentioned above. These HRU simulation results are combined for each subbasin, and then routed through the watershed's stream network.

\section{Curve Number Approach Used by SWAT2005}

To model surface runoff for any given day, the first step that SWAT2005 takes is to assign an initial NRCS Curve Number $(\mathrm{CN})$ is assigned for each specific landuse/soil combination in the watershed, and these values are read into the SWAT program. SWAT then calculates upper and lower limits for each CN following a probability function described by the NRCS to account for varying 
antecedent moisture conditions (CN-AMC) (USDA-NRCS, 2004). SWAT determines an appropriate $\mathrm{CN}$ for each simulated day by using this $\mathrm{CN}-\mathrm{AMC}$ distribution in conjunction with daily soil moisture values determined by the model. This daily $\mathrm{CN}$ is then used to determine a theoretical storage capacity, $S$, of the watershed for each day the model is run. The storage is then indirectly used to calculate runoff volume, $Q$ :

$$
\begin{aligned}
& C N=\frac{1000}{10+S / 25.4} \\
& Q=\frac{\left(P-I_{a}\right)^{2}}{\left(P-I_{a}\right)+S}
\end{aligned}
$$

eq. 1

eq. 2

where $S$ is watershed storage, $P$ is precipitation, and $I_{a}$ is initial abstraction. All terms are in $\mathrm{mm}$ of water, and by convention $l_{a}$ is assumed to be equal to $0.2 * S$.

\section{Water Balance Approach Used by SWAT-WB}

To replace the $\mathrm{CN}$, a simple soil profile water balance was calculated for each day of simulation. While SWAT's soil moisture routine greatly simplifies processes that govern water movement through porous media (in particular, partly-saturated regions), for a daily model the approach can be shown to be acceptable (Guswa et al., 2002). These inherent soil moisture routines are then used by SWAT-WB to determine the degree of saturation-deficit for each soil profile for each day of simulation. This saturation-deficit (in $\mathrm{mm} \mathrm{H}_{2} \mathrm{O}$ ) is termed the available soil storage, $T$ :

$$
\tau=E D C(\varepsilon-\theta)
$$

eq. 3

where $E D C$ is the effective depth of the soil profile (unitless), $\varepsilon$ is the total soil porosity $(\mathrm{mm})$, and $\theta$ is the volumetric soil moisture for each day $(\mathrm{mm})$. The porosity is a constant value for each soil type, whereas $\theta$ varies by the day and is determined by SWAT's soil moisture routines. The effective depth, $E D C$, a calibration parameter ranging from zero to one, is used to represent the portion of the soil profile used in calculating the saturation deficit. By including this adjustment to the available storage, the amount of water able to infiltrate each day will be controlled by the EDC. EDC will then be spatially varied in such a way that low values are assigned to areas with a high likelihood of saturation, and higher EDCs will be used for areas where not much surface runoff is generated via saturation excess. 
This spatially adjusted available storage is then used to determine what portion of rainfall events will infiltrate and what portion will runoff:

$$
Q=\left\{\begin{array}{cc}
0, & \text { if } P<\tau \\
P-\tau, & \text { if } P \geq \tau
\end{array}\right.
$$

eq. 4

where $Q$ is surface runoff $(\mathrm{mm})$ and $P$ is precipitation $(\mathrm{mm})$.

The available storage, $T$, is calculated each day prior to the start of any rain event. Once precipitation starts, a portion of the rain, equal in volume to $T$, will infiltrate the soil. If the rain event is larger in volume than $T$, the soil profile will be saturated and surface runoff will occur. If the rain event is less than $T$, the soil will not be saturated and there will be no surface runoff. By using this simple saturation-deficit term, SWAT-WB represents saturation-excess process and is no longer reliant upon the $\mathrm{CN}$ method.

This theoretical documentation was adapted from the SWAT-WB article available from the SWAT-WB website and is meant to provide a brief overview of the changes made to the original version of SWAT. The official SWAT-WB paper should be referred to for a full discussion of the model and its successful application in two test watersheds. For a full description of the original SWAT program please refer to either the official SWAT website (www.brc.tamus.edu/swat) or to the comprehensive article by Gassman et al. (2007). Similarly, a full description of the Curve Number approach utilized by SWAT2005 is available in the NRCS's National Engineering Handbook.

These references are available from:

Gassman, P.W., Reyes, M.R., Green, C.H., \& Arnold, J.G. (2007). The Soil and Water Assessment Tool: Historical development, applications, and future research directions. Transactions of the American Society of Agricultural and Biological Engineers. 50(4), 1211-1250

USDA-NRCS. (2004). Estimation of direct runoff from storm rainfall. In National Engineering Handbook, Part 630: Hydrology. Retrieved January 15, 2008, from http://policy.nrcs.usda.gov/viewerFS.aspx? hid=21422. 


\section{REFERENCES}

Arnold, J.G., Muttiah R.S, Srinivasan R., \& Allen, P.M. (2000). Regional estimation of base flow and groundwater recharge in the Upper Mississippi Basin. Journal of Hydrology. 227(1-4), 21-40.

Ayenew, T., \& Gebreegziabher, Y. (2006). Application of a spreadsheet hydrological model for computing long-term water balance of Lake Awassa, Ethiopia. Hydrological Sciences. 51(3), 418-431.

Beven, K.J., \& Kirkby M.J. (1979). Towards a simple physically-based variable contributing model of catchment hydrology. Hydrologic Sciences Bulletin. 24(1), 43-69.

Bosznay, M. (1989). Generalization of SCS curve number method. Journal of Irrigation and Drainage Engineering. 115(1), 139-144.

Bryant, R.D., Gburek, W.J., Veith,T.L., \& Hively, W.D. (2006). Perspectives on the potential for hydropedology to improve watershed modeling of phosphorus loss. Geoderma. 131, 299-307.

Chanasyk, D.S., Mapfumo, E., \& Williams, W. (2003). Quantification and simulation of surface runoff from fescue grassland watersheds. Agricultural Water Managment. 59(2), 137-153.

Conway, D. (1997). A water balance model of the upper Blue Nile in Ethiopia. Hydrological Sciences. 42(2), 265-286 
Easton, Z.M., Fuka, D.R., Walter M.T., Cowan, D.M., Schneiderman, E.M., \& Steenhuis, T.S. (2008). Re-conceptualizing the Soil and Water Assessment Tool (SWAT) model to predict runoff from variable source areas. Journal of Hydrology. 348(3-4), 279-291.

FAO-AGL. (2003). World Reference Base: Map of World Soil Resources. Retrieved from http://www.fao.org/ag/agl/agll/wrb/soilres.stm.

Frankenberger, J.R., Brooks, E.S., Walter, M.T., Walter, M.F., \& Steenhuis, T.S. (1999). A GIS-based variable source area model. Hydrologic Processses. 13(6), 804-822.

Garen, D.C., \& Moore, D.S. (2005). Curve number hydrology in water quality modeling: Uses, abuses, and future directions. Journal of the American Water Resources Association. 41(2), 377-388.

Gassman, P.W., Reyes, M.R., Green, C.H., \& Arnold, J.G. (2007). The Soil and Water Assessment Tool: Historical development, applications, and future research directions. Transactions of the American Society of Agricultural and Biological Engineers. 50(4), 1211-1250.

Guswa, A.J., Celia, M.A., \& Rodriguez-Iturbe, I. (2002). Models of soil dynamics in ecohydrology: A comparative study. Water Resources Research. 38(9), 1166-1181.

Hawkins, R.H. (1979). Runoff curve numbers from partial area watersheds. Journal of the Irrigation and Drainage Division, ASCE. 105(4), 375-389. 
Hjelmfelt, A.T. (1991). Investigation of curve number procedure. Journal of Hydraulic Engineering. 117(6), 725-737.

Johnson, P.A., \& Curtis, P.D. (1994). Water balance of Blue Nile river basin in Ethiopia. Journal of Irrigation and Drainage Engineering. 120(3), 573590.

Kim, N.W., \& Lee, J. (2008). Temporally weighted average curve number method for daily runoff simulation. Hydrological Processes. 22, 49364948.

Kim, U., \& Kaluarachchi, J.J. (2008). Application of parameter estimation and regionalization methodologies to ungauged basins of the upper Blue Nile river basin, Ethiopia. Journal of Hydrology. 362, 39-56

King, K.W., Arnold, J.G., \& Binger,R.L. (1999). Comparison of Green-Ampt and Curve Number Methods on Goodwin Creek Watershed Using SWAT. Transactions of the American Society of Agricultural Engineers. 42(4), 919-925.

Liu, B.M., Collick, A.S., Zeleke, G., Adgo, E., Easton, Z.M., \& Steenhuis, T.S. (2008). Rainfall-discharge relationships for a monsoonal climate in the Ethiopian highlands. Hydrological Processes. 22(7), 1059-1067.

Lyon, S.W., Walter, M.T., Gerard-Marchant, P., \& Steenhuis, T.S. (2004). Using a topographic index to distribute variable source area runoff predicted with the SCS curve-number equation. Hydrological Processes. 18, 2757-2771. 
Lyon, S.,W, Seibert, J., A.J., Lembo, Walter, M.T., \& Steenhuis, T.S. (2006a). Geostatistical investigation into the temporal evolution of spatial structure in a shallow water table. Hydrology and Earth System Sciences. 10(1), 113-125.

Lyon, S.W., McHale, M.R., Walter, M.T., \& Steenhuis, T.S. (2006b). The impact of runoff generation mechanisms on the location of critical source areas. Journal of the American Water Resources Association. $42,793-804$.

Mehta, V.K., Walter, M.T., Brooks, E.S., Steenhuis, T.S., Walter, M.F., Johnson, M., Boll, J., Thongs, D. (2004). Evaluation and application of SMR for watershed modeling in the Catskill mountains of New York State. Environmental Modeling \& Assessment. 9(2), 77-89.

Moriasi, D.N., Arnold, J.G., Van Liew, M.W., Bingner, R.L., Harmel, R.D., \& Veith, T.L. (2007). Model evaluation guidelines for systematic quantification of accuracy in watershed simulations. Transactions of the American Society of Agricultural and Biological Engineers. 50(3), 885900.

NCDC. (2007). Global Summary of the Day. In National Climatic Data Center's NNDC Climate Data Online. Retrieved November 24, 2007, from www7.ncdc.noaa.gov/CDO/cdoselect.cmd?datasetabbv=GSOD. 
Page,T., Haygarth, P.M., Beven K.T., Joynes, A., Butler, T., Keeler, C., Freer, J., Owens, P.N., Wood, G.A. (2005). Spatial variability of soil phosphorus in relation to the topographic index and critical source areas: Sampling for assessing risk to water quality. Journal of Environmental Quality. 34, 2263-2277.

Ponce, V.M., \& Hawkins, R.H. (1996). Runoff curve number: Has it reached maturity? Journal of Hydrologic Engineering. 1(1), 11-19.

Setegn, S.G., Srinivasan, R., \& Dargahi, B. (2008). Hyrdological modeling in the Lake Tana basin, Ethiopia using SWAT model. The Open Hydrology Journal. 2, 49-62.

Schneiderman, E.M., Pierson, D.C., Lounsbury, D.G., \& Zion, M.S. (2002). Modeling the hydrochemistry of the Cannonsville Watershed with Generalized Watershed Loading Functions (GWLF). Journal of the American Water Resources Association. 38(5), 1323-1347.

Schneiderman, E.M., Steenhuis, T.S., Thongs, D.J., Easton, Z.M., Zion, M.S., Neal, A.L., Mendoza, G.F., \& Walter, M.T. (2007). Incorporating variable source area hydrology into a curve-number-based watershed model. Hydrological Processes. 21, 3420-3430.

Sharma, S.K., Mohanty, B.P., \& Zhu, J.T. (2006). Including topography and vegetation attributes for developing pedotransfer functions. Soil Science Society of America Journal. 70, 1430-1440. 
Sheridan, J.M., \& Shirmohammadi, A. (1986). Application of curve number procedure on coastal plain watersheds. Proceedings from: The 1986 Winter Meeting of the American Society of Agricultural Engineers. Paper No. 862505. Chicago, IL: ASAE.

Steenhuis, T.S., Winchell, M., Rossing, J., Zollweg, J.A., \& Walter, M.F. (1995). SCS runoff equation revisited for variable-source runoff areas. Journal of Irrigation and Drainage Engineering. 121(3), 234-238.

Thompson, J.A., Pena-Yewtukhiw, E.M., \& Grove, J.H. (2006). Soil landscape modeling across a physiographic region: Topographic patterns and model transportability. Geoderma. 133, 57-70.

Tolson, B.A., \& Shoemaker, C.A. (2005). Dynamically dimensioned search algorithm for computationally efficient watershed model calibration. Water Resources Research. 43, W01413-W01429.

USDA-NRCS. (2000). Soil Survey Geographic (SSURGO) database for Delaware County, New York. Retrieved from http://www.nrcs.usda.gov/ products/datasets/ssurgo.

USDA-NRCS. (2004). Estimation of direct runoff from storm rainfall. In National Engineering Handbook, Part 630: Hydrology. Retrieved January 15, 2008, from http://policy.nrcs.usda.gov/viewerFS.aspx? hid=21422. 
Walter, M.T., Mehta, K., Marrone, A.M., Boll, J., Gérard-Merchant, P., Steenhuis, T.S., \& Walter, M.F. (2003). A Simple estimation of the prevalence of hortonian flow in New York City's watersheds. Journal of Hydrologic Engineering. 8(4), 214-218.

Wang, X., Shang, s., Yang, W., \& Melesse, A.M. (2008). Simulation of an agricultural watershed using an improved curve number method in SWAT. Transactions of the American Society of Agricultural and Biological Engineers. 51(4), 1323-1339.

White, E.D., Feyereisen, G.W., Veith, T.L., \& Bosch, D.D. (2009). Improving daily water yield estimates in the Little River watershed: SWAT adjustments. Transactions of the American Society of Agricultural and Biological Engineers. 52(1), 69-79.

Woodward, D.E., \& Cronshey, R. (1992). Investigation of curve number procedure - discussion. Journal of Hydraulic Engineering. 118(6), 951. 